\title{
Introduction to piezoelectricity and electrospun piezoelectric materials and devices
}

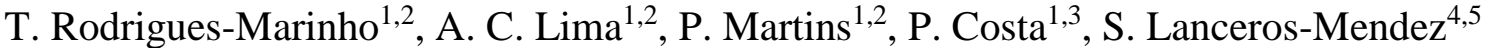 \\ ${ }^{1}$ Centre of Physics, University of Minho, 4710-057, Braga, Portugal \\ 2 IB-S Institute of Science and Innovation for Sustainability, Universidade do Minho, 4710-057, Braga, \\ Portugal \\ ${ }^{3}$ Institute for Polymers and Composites IPC/I3N, University of Minho, 4800-058 Guimarães, Portugal \\ ${ }^{4}$ BCMaterials, Basque Center for Materials, Applications and Nanostructures, UPV/EHU Science Park, \\ 48940 Leioa, Spain \\ ${ }^{5}$ IKERBASQUE, Basque Foundation for Science, 48013, Bilbao, Spain
}

\begin{abstract}
Piezoelectric materials are increasingly being used in a wide range of applications. Single crystals, ceramics and polymers are all being used sensors, actuators and energyharvesting applications. Among the most used piezoelectric materials are lead zirconate titanate $(\mathrm{PZT})$ and barium titanate $\left(\mathrm{BaTiO}_{3}\right)$ ceramics and the polymer poly(vinylidene fluoride) (PVDF). Polymer-based composites including high dielectric and piezoelectric ceramic nano- or microparticles are also largely investigated to take advantage of the advantageous properties of both polymers and ceramics. Among the different processing methods, electrospinning allows the development of piezoelectric nano- and microfibers opening a distinct range of applications in electronics, energy generation and storage or membranes for water and air remediation.
\end{abstract}

\section{Keywords}

Piezoelectricity; piezoelectric materials; sensors; actuators; energy harvesting; electrospinning

\section{Introduction}

From the beginning of the new millennium, and more particularly during the last decade, strong advances have taken place in science and technology, resulting from an interplay between different innovation areas and disciplines [1,2].

Such approach is being particularly successful in the development, optimization and application of smart and multifunctional materials, which takes advantage of knowledge on biology, physics, chemistry, nanotechnology and materials science, as well as mechanical and electrical engineering. This leads not just to an increasing number of high performance smart and multifunctional materials, but also to the emergence of disruptive applications based on them [2, 3]. 
Further, smart materials associated with the Internet of Things (IoT) concept represent the innovative vehicle to reach wireless, sustainable and interconnected autonomous smart systems and cities [3].

There are different types of smart materials, including shape memory, piezoelectric, piezoresistive, magnetorheological, magnetostrictive, magnetoelectric, electrorheological, and chromic [4-9], among others, each of them exhibiting a specific relation between the external stimulus and the materials response, which can be used for a variety of applications such as sensors, actuators, energy harvesting and in the biomedical field, among others [2].

The electromechanical transduction capability of piezoelectric materials, which converts mechanical energy into electrical energy or vice versa, allows to accurately detect physical parameters such as pressure, mass, or acceleration, among others [10], being therefore applied in a large variety of devices, including force, touch and strain sensors, self-powered devices, acoustic and ultrasonic tools, precision positioning instruments, fluid injection systems and damping controllers [9]. All of these applications are based on the piezoelectric effect, discovered in 1880 by the Curie brothers [11].

Materials showing the piezoelectric effect are typically clarified as a function of the piezoelectric coefficients $d_{i j}$, quantifying the mechanical to electrical conversion, exemplified in Figure 1. 


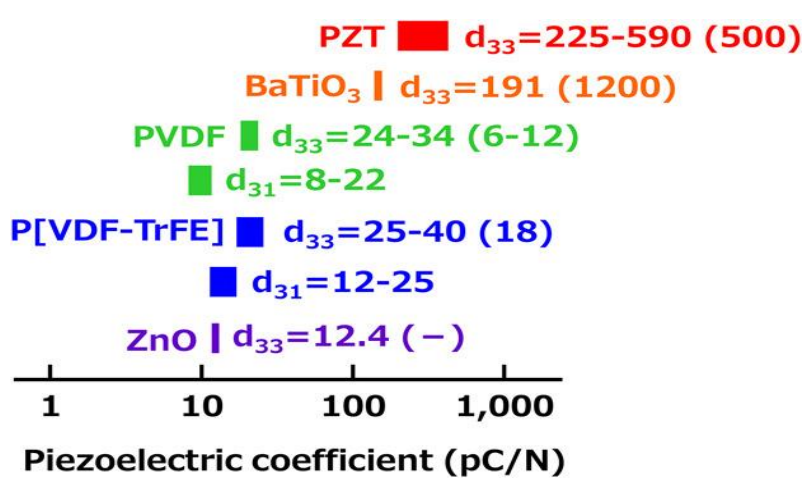

Figure 1- Piezoelectric coefficient ranges of various piezoelectric materials; $d_{33}$ and $d_{31}$ are the modulus of the longitudinal and transverse piezoelectric coefficients. The values in parentheses correspond to the relative permittivity. Numerical figures are represented as absolute values. With permission from Narita et al. [12].

Barium titanate $\left(\mathrm{BaTiO}_{3}\right)$, lead zirconate titanate $\left(\mathrm{Pb}\left(\mathrm{Zr}_{1-\mathrm{X}}, \mathrm{Ti}_{\mathrm{X}}\right) \mathrm{O}_{3}\right.$, known as $\left.\mathrm{PZT}\right)$, and related materials are the most used piezoelectrics due to their highest piezoelectric response (Figure 1), nevertheless some disadvantages, such as the mechanical brittleness or high rigidity hinder their application on devices that require high flexibility $[12,13]$. To solve such issues, polymer-based piezoelectric composites, have emerged as a solution. Within all possible composites the ones with 0-3 connectivity, i.e. randomly dispersed piezoceramic particles in a non-piezoelectric polymer matrix, exhibit the lowest piezoelectric response (20-30 times less), when compared with polymer-ceramic composites with 1-3 connectivity, i.e. ceramic fibres in a non-piezoelectric polymer matrix, or 2-2 connectivity, i.e. ceramic laminates in a non-piezoelectric polymer matrix [12].

More recently, piezoelectric polymers such polyvinylidene fluoride (PVDF), and its copolymers, such as polyvinylidene fluoride trifluoroethylene (PVDF-TrFE), are being increasingly used due to their flexibility, high elastic compliance, strong electrical dipole moment of the PVDF monomer unit $\left(5-8 \times 10^{-30}\right.$ C.m), high chemical and radiation resistance, lightweight, additive manufacturing compatibility and low-cost $[2,14]$.

Nowadays, piezoelectric materials have become increasingly explored to effectively harvest energy from different mechanical sources such as human motion, low-frequency seismic vibrations and acoustic noise (Figure 2). The harvested energy is being used to power sensors, biosensors and actuators [15], being particularly suitable for to power wearable electronic devices [16]. 


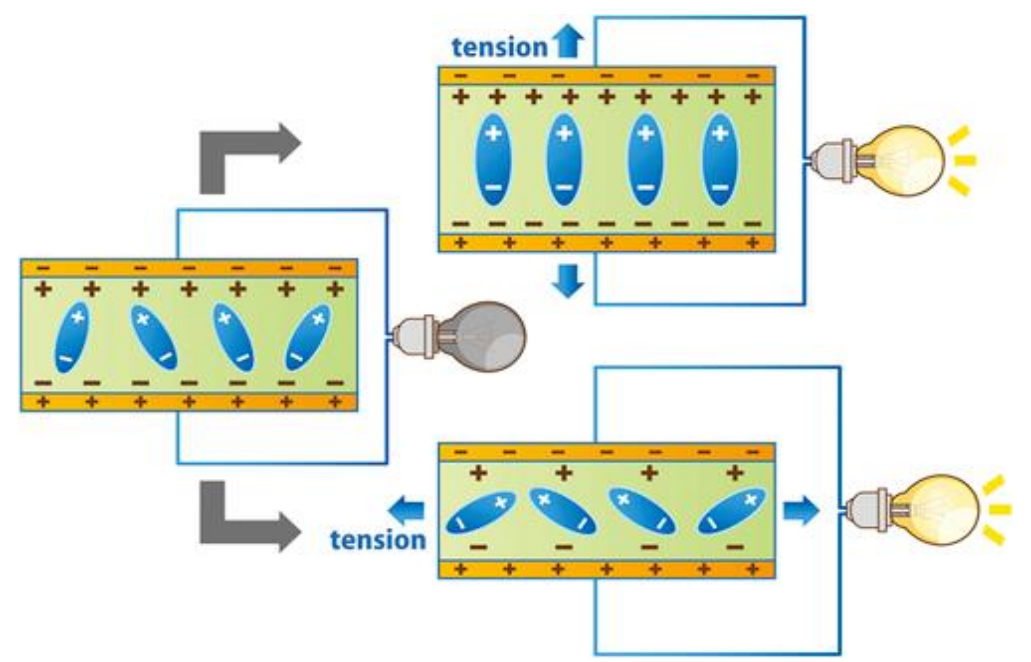

Figure 2- Piezoelectric effect for energy harvesting. Image taken with permission from Narita et al. [12].

\section{Piezoelectricity: fundamentals and energy generation}

The word piezoelectricity comes from Greek piezein that means "to press" and therefore can be understood as the capability of specific materials to develop an electrical voltage under the application of a certain mechanical stress.

The piezoelectric effect is strongly related to the crystalline structure of materials. From the 32 crystal classes, 21 are non-centrosymmetric, showing 20 of them piezoelectricity. Of the 20 piezoelectric classes, half of them are pyroelectric, developing a voltage as a response of a temperature variation, and some of them can be also ferroelectric (the dipolar moment can be reversed in an applied electric field) [17].

The piezoelectricity is thus established in non-symmetric crystals with polar structures and can be described as the capability of these materials to develop an electrical voltage under the application of a mechanical stimulus, or the opposite, changing their geometry under an electric voltage field. The piezoelectric effect is described as direct and the inverse. The direct effect is when the material is subjected to external mechanical stimulus and the dipoles are oriented causing that the crystal develops positive and negative charges on each surface, resulting in an electric field within the material. The inverse piezoelectric effect describes the geometric changes on the crystal when it is subjected to an external electric field. The reorientation of the dipolar moments under electric field causes the deformation of the crystal, linearly proportional to the electric field applied $[18]$. 
The direct and inverse piezoelectric effects were discovered by in 1880 (by Pierre and Jacques Curie) and 1881 (by Lippmann), respectively, and can be described by the constitutive equations [18]:

$$
\begin{aligned}
& D_{i}=d_{i k l} T_{k l}+\varepsilon_{i k}^{T} E_{k} \\
& s_{i j}=S_{i j k l}^{E} T_{k l}+d_{k i j} E_{k}
\end{aligned}
$$

where the subscripts $i, j, k$ and $l$ take values of 1,2 and 3. $S$ and $T$ is the stress and strain tensors, respectively, the electric displacement and field vectors are $D$ and $E$, respectively. Further, the elastic compliance matrix at constant electric field is $s, d$ is the piezoelectric strain coefficients, and $\varepsilon$ represents the dielectric permittivity at constant stress. In both equations, $d$ represents the charge variation induced by a given force in the absence of an electric field (short-circuit electrical condition), or the deflection caused by an applied voltage in the absence of an applied force (stress-free mechanical condition) [18] as illustrated in Figure 3.

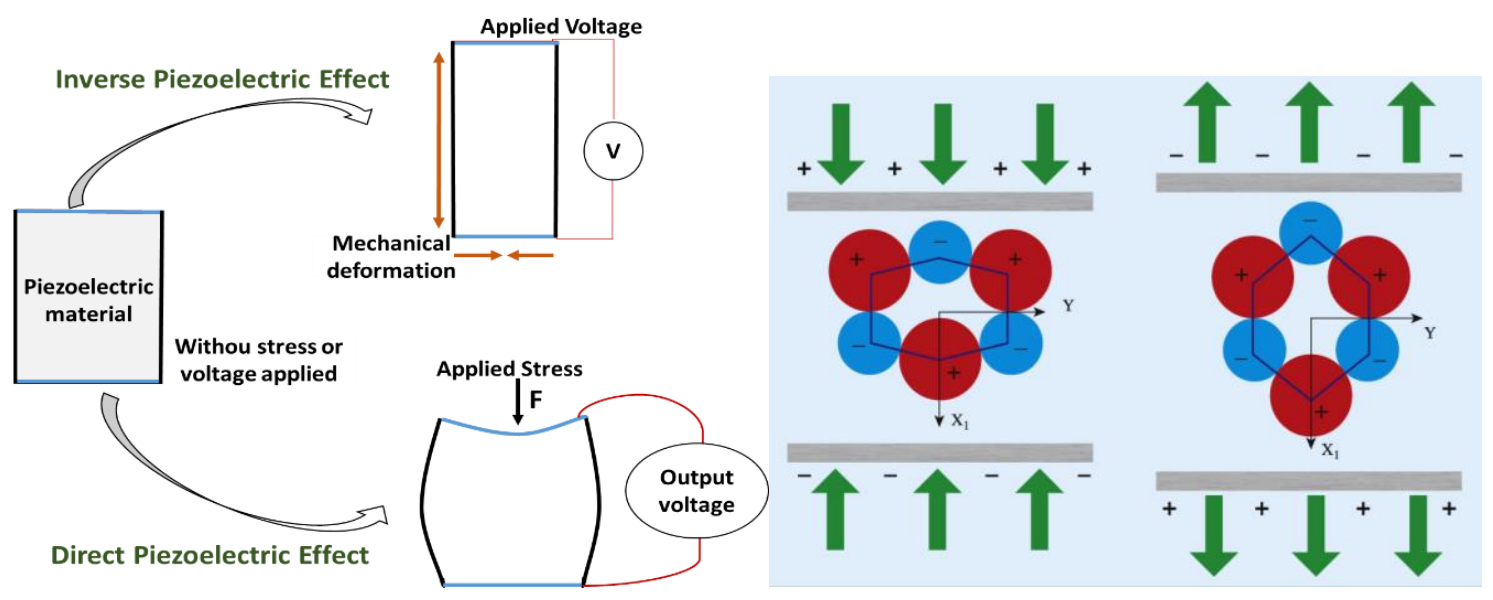

Figure 3- Schematic representation of the piezoelectric direct and inverse effects. B) Illustration of the direct piezoelectric effect induced charges under mechanical compressive and tensile stress. Adapted with permission from [19].

\subsection{Piezoelectric coefficients}

The most used piezoelectric coefficients are the $d_{31}$ and $d_{33}$ known as the transversal and longitudinal coefficients, respectively (Figure 4). They are typically represented in units of meters per volt $(\mathrm{m} / \mathrm{V})$ or coulombs per newton $(\mathrm{C} / \mathrm{N})$. Each of the coefficients describe 
the electric polarization generated in one direction due to the application of a transversal or parallel applied stress.

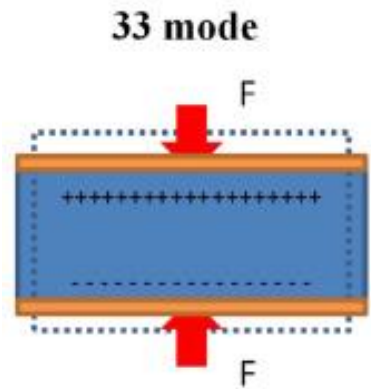

(a)

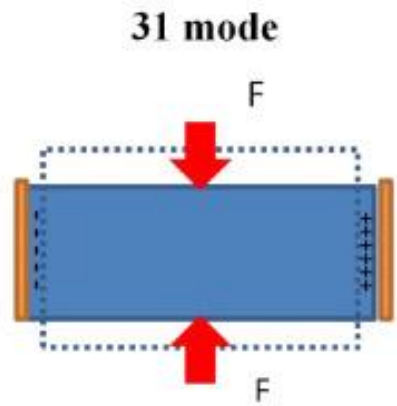

(b)

Figure 4- The piezoelectric transduction modes. Adapted with permission from [20].

A piezoelectric materials converts mechanical into electrical energy (or vice versa) and the conversion efficiency is quantified by the electromechanical coupling coefficient, $k$, being closely related to the bandwidth of resonant devices, and expressed as [21]:

$$
k_{i j}=\frac{d_{i j}}{\sqrt{\varepsilon_{i i}^{\sigma} S_{j j}^{E}}}
$$

\subsection{Energy-harvesting}

Energy harvesting focus in the recovery of environmental energy that would be wasted otherwise, from sources such as force/pressure, heat and vibration/movement. Typically, that energy can be used for powering low-power devices, in particular for applications in remote or inaccessible zones, where battery replacement is complicated or even impossible [22].

Piezoelectric, thermoelectric and electromagnetic are the most used systems to harvesting energy from wasted source powers, the harvested power typically ranging from nano- to microwatts per $\mathrm{cm}^{2}$.

Vibrations are the most used source for energy harvesting using microelectromechanical systems (MEMS). The most used mechanical to electrical transduction mechanisms used are piezoelectric, electrostatic and electromagnetic [23], ceramics being the most used materials for this application, independently of the transduction mechanism, leading to $\mu \mathrm{W}$ of output harvested power [23]. On the other hand, ceramics area not suitable for large area applications, due to high costs and mechanical limitations of materials. 
Thus, polymers are being explores and, in particular, PVDF and their copolymers also becoming widely used in piezoelectric applications. Further, PVDF-based composites with high dielectric materials (ceramics or single crystals) allow to combine the mechanical properties of polymers and the high dielectric constant of the brittle ceramic materials. Polymer-based piezoelectric devices can produce output voltages and currents near some hundreds volt and tens of micro amperes, respectively [22-25].

\section{Introduction to electrospinning technique}

The development of nanotechnology platforms allowing to produce materials in nanofiber shape has a strong influence in different areas of science and engineering, contributing to society with applications on electronics, energy storage, renewable energy, water and air filtration, oil and gas industries, food industry, pharmaceutical industry, healthcare and consumer goods, among others [26, 27].

There are different methods for the fabrication of nanofibers (NFs) such as electrospraying [28], self-assembly [29], sol-gel [30], rotary jet spinning [31], electrospinning (allowing to produce random, aligned, core-shell, and vertical nanofibers) [32-34], phase separation [35] and melt-blown protocols [36], among others. Electrospinning, due to its high efficiency, has emerged as one of the preferred techniques for nanofiber production. The electrospinning process is continuous, scalable, a large variety of materials can be processed by this technique a allows outstanding control over nanofiber dimensions and orientation. Also, synthesis of nanoparticles by electrospraying overcomes limitations associated with other fabrication processes, such as emulsion/evaporation, coacervation, spray-drying, nanoprecipitation and microfluidic methods. Therefore, synthesis of nanomaterials by electrospinning or electrospraying is currently an essential component of nanomaterial's research [37].

Electrospinning and electrospraying are technologies where a polymeric solution can be spun or sprayed by the application of a high electric field to obtain fibers or spheres, respectively $[38,39]$. These electrodynamic processes (Figure 5a) and b)), use almost the same setup and equipment, that consists of four main components $[38,40]$ :

I. a high voltage source (in a typical range 1 to $30 \mathrm{kV}$ ) mostly operated in direct current (DC) mode, though alternating current mode is also possible;

II. a blunt ended stainless-steel needle or capillary;

III. a syringe pump; 
IV. a grounded collector either as a flat plate or rotating drum.

In electrospinning of polymer, a strong electric field is applied to a droplet formed by a polymer solution or polymer melt at the tip of a die, which acts as one of the electrodes. The charging of the fluid leads to a conical deformation of the droplet (Taylor cone) and finally to the ejection of a jet from the tip of the cone [41].

The charged jet is accelerated towards the counter electrode and thins rapidly, due to the elongation and evaporation of the solvent until solid fibers are deposited into the substrate located on top of the counter electrode [42]. This process is characterized by a rapid and strong elongational deformation of the spinning jet due to a bending instability, which occurs during the course of the fiber formation. The deformation of the jet normally gives rise to nanofibers that display a strong orientation of the chain molecules as well as of the crystals. Such orientations cause significant increases of the mechanical stiffness and strength of the fibers [41].
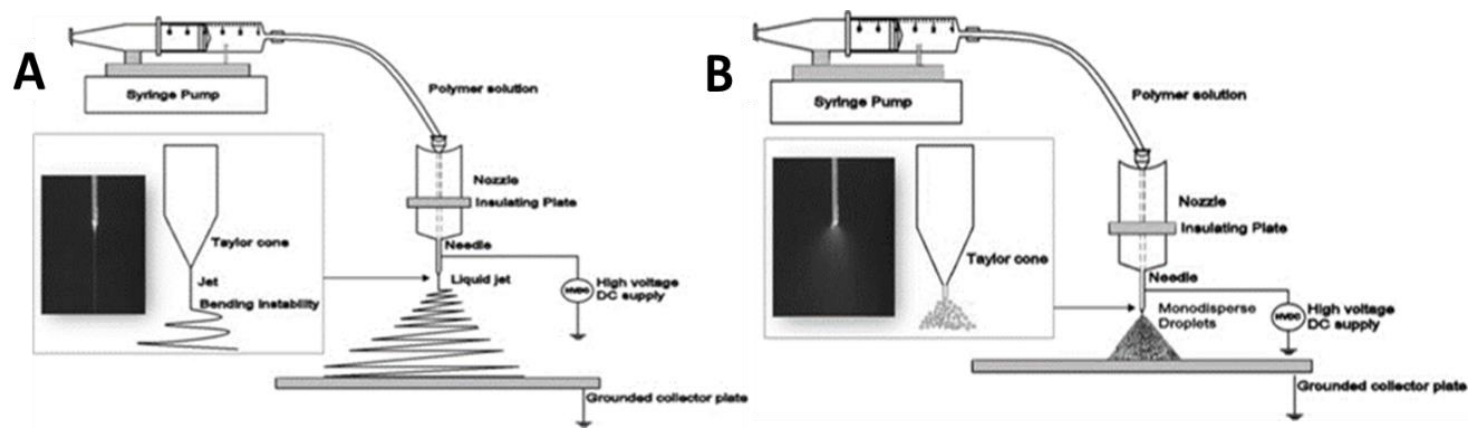

Figure 5- A typical laboratory scale, a) electrospinning setup and b) electrospraying setup. Images taken with permission from [39].

Electrospraying, Figure $5 \mathrm{~b}$, is a variation of the electrospinning method, which was initially applied in medicine with the aim to produce materials able to encapsulate drugs [43]. Vonnegut and Neubauer [44] were pioneers in applying voltage to produce micrometer-sized spherical particles for application as sprays. Today, this technology is expanding due to its simplicity and low-cost [43].

The major distinction between electrospinning and electrospraying is the polymer content on the polymeric solution. When the solution concentration is high, the jet from the Taylor cone is stabilized, and elongation takes place by whipping instability mechanism[45]. If the solution concentration is low, the jet is destabilized and fine droplets are formed. 
These highly charged droplets are self-dispersed in space, preventing droplet agglomeration and coagulation.

Further, evaporation of the solvent leads to contraction and solidification of droplets resulting in solid polymeric particles deposited on the grounded collector [39].

Figure 6 shows some of the advantages of electrospun and electrosprayed products.

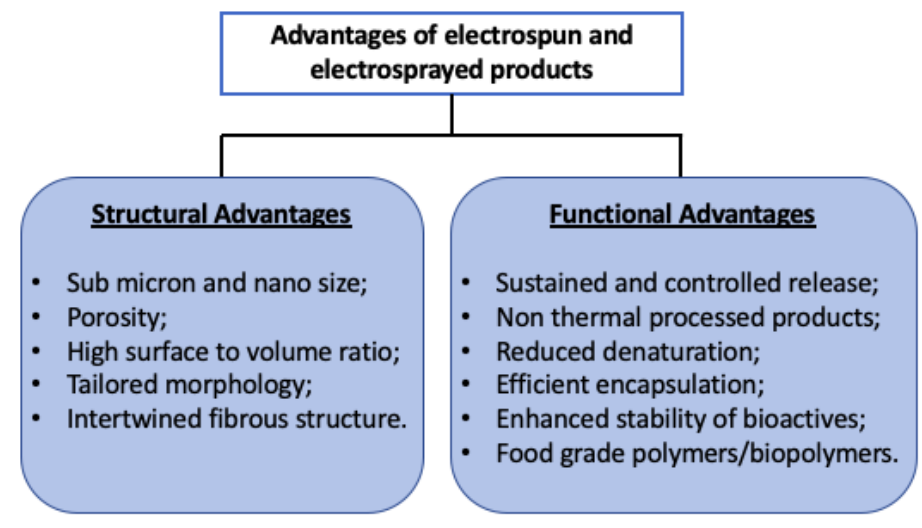

Figure 6- Main advantages of electrospun and electrosprayed materials.

Nanofibers show interesting electric, thermal, optical, magnetic, and mechanical properties due to effects related to their small-size, increased interface, and surface area. Furthermore, NFs prepared by electrospinning shown high surface area-to-volume ratio (SVR), high overall porosity of the fiber mats, and a unique web structure that are essential, for example, for energy conversion and storage applications [46].

Electrospinning also allows the production of NFs with different orientation and hierarchical structures. The orientation of NF includes randomly oriented and aligned structures as shown in Figure 7 [47].

Particularly, the well-aligned NF are often required for energy harvesting devices or scaffolds for some tissue engineering applications[48, 49]. It is important to notice that the fiber collector plays an essential role in obtaining nanofiber orientation. Thus, several methods have been developed to enhance alignment of electrospun NFs by using special designed collectors, such as rotating drums [50], metal frames [51], or two conductive substrates separated by a gap [52]. In addition, a liquid system combined with a rotating mandrel has been developed to produce a continuous yarn of electrospun fibers [53].

Nowadays, a large variety of polymers have been successfully electrospun into ultra-fine fibers with diameters ranging from $<3 \mathrm{~nm}$ to over $1 \mu \mathrm{m}$ [54]. 


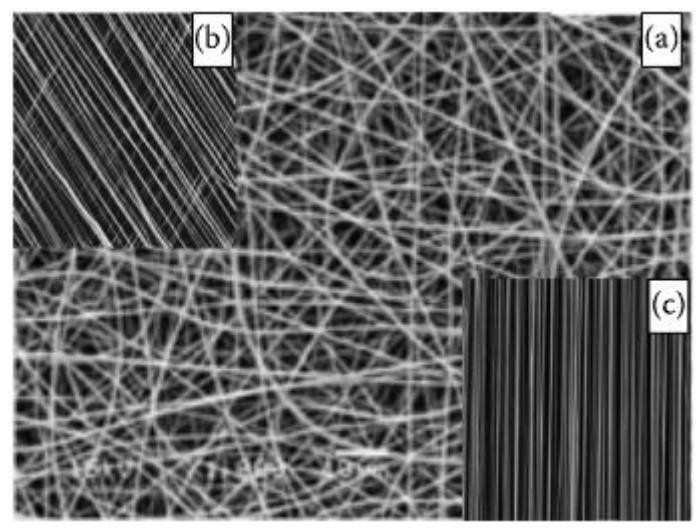

Figure 7- Scanning electron micrographs of electrospun (a) random NF, (b) aligned fibers at a specific angle, and (c) aligned fibers. Image taken with permission from [47].

\subsection{Electrospinning of piezoelectric materials}

Polymers are typically dissolved into solvents before electrospinning and the same polymer can be dissolved in different solvents to tune electrospun processing conditions and therefore final fiber mat properties. A summary of some relevant polymers which have been successfully electrospun into fibers is listed in Table 1 [37] together with the used solvents, polymer concentrations and proposed or perspective applications of the corresponding fibers.

Among polymers, piezoelectric polymers stand out as an interesting material for a new generation of applications such as wearable smart materials, energy harvesters devices, sensors and actuators [55].

Table 1- Representative polymer that have been electrospun from solution.

\begin{tabular}{|c|c|c|c|c|}
\hline Polymer & Solvent & Concentration & Application & Ref. \\
\hline PLA & Dichlormethane & $5 \mathrm{wt} . \%$ & Sensor, Filter & {$[56]$} \\
\hline PANI/PS & Camphorsulfonic acid & $2 \mathrm{wt} . \%$ & Conductive fiber & {$[57]$} \\
\hline $\begin{array}{c}\text { Silk-like polymer } \\
\text { with fibronectin } \\
\text { functionality }\end{array}$ & Formic acid & $0.8-16.2 \mathrm{wt} . \%$ & $\begin{array}{c}\text { Implantable } \\
\text { device }\end{array}$ & {$[58]$} \\
\hline PVDF & $\begin{array}{c}\text { Dimethyl formamide: } \\
\text { dimethylacetamide }\end{array}$ & $20 \mathrm{wt} . \%$ & Flat Ribbons & {$[59]$} \\
\cline { 3 - 5 } & $\begin{array}{c}\text { Acetone, acetic acid, } \\
\text { dimethylacetamide }\end{array}$ & $12.5-20 \%$ & Membrane & {$[61]$} \\
\hline CA & $\begin{array}{c}\text { Tetrahydrofuran: } \\
\text { dimethylformamide }\end{array}$ & $1 \mathrm{~g} / 20 \mathrm{ml}$ & $\begin{array}{c}\text { Tissue } \\
\text { engineering }\end{array}$ & {$[61]$} \\
\hline PLGA
\end{tabular}




\begin{tabular}{|c|c|c|c|c|}
\hline nylon-4,6, PA-4,6 & Formic acid & $10 \mathrm{wt} \%$, & $\begin{array}{c}\text { Transparent } \\
\text { composite }\end{array}$ & {$[62]$} \\
\hline EVA & $\begin{array}{c}\text { Isopropanol/water: } \\
70 / 30(\% \mathrm{v} / \mathrm{v})\end{array}$ & $2.5-20 \%(\mathrm{w} / \mathrm{v})$ & Biomedical & {$[63]$} \\
\hline PVP & Tetrahydrofuran & $20,60 \%(\mathrm{w} / \mathrm{v})$ & $\begin{array}{c}\text { Antimicrobial } \\
\text { agent }\end{array}$ & {$[64]$} \\
\hline PAA-PM & Dimethyl formamide & $26 \mathrm{wt} . \%$ & Optical Sensor & {$[65]$} \\
\hline PS & Tetrahydrofuran & $15 \mathrm{wt} . \%$ & Catalyst, filter & {$[66]$} \\
\hline PEO & Distilled water: ethanol & $4 \mathrm{wt} \%$ & $\begin{array}{c}\text { Microelectronic } \\
\text { wiring, } \\
\text { interconnects }\end{array}$ & {$[67]$} \\
\hline
\end{tabular}

Abbreviatures: Polylactic acid, PLA; Polyaniline, PANI; Polystyrene, PS; Poly(vinylidene fluoride), PVDF; Cellulose acetate, CA; Poly Lactic-co-Glycolic Acid, PLGA; Poly (ethylene-co-vinyl alcohol), EVA; Poly vinyl phenol, PVP; Poly(acrylic acid)poly(pyrene methanol) PAA-PM; Poly(ethylene oxide) PEO

From all the piezoelectric polymer, PVDF and its copolymers are the ones with the larger piezo, pyro and ferroelectric response. PVDF has five crystalline phases (Figure 8) and among these five crystalline phases, the $\alpha$ phase is nonpolar [68] and the $\beta$-phase is polar, providing the highest electroactive response [41, 69]. The polar $\beta$-phase can be obtained through mechanical stretching [70, 71], low temperature solvent evaporation [72], high electric field poling [73] or the addition of specific fillers including ionic liquids [74], ferrites[75] or conductive additives [76, 77], among others [2, 78, 79].

The formation of continuous fibers from PVDF solutions or melts under strong electrostatic fields allows the production of ultrafine piezoelectric PVDF nanofibers. Thus, randomly oriented electrospun PVDF nanofibrous membranes lead to a piezoelectric output of $140 \mathrm{mV}$ under $5 \mathrm{~N}$ loading [80]. Aligned PVDF nanofibers on a polyethylene terephthalate (PET) substrate under an applied loading frequency of $7 \mathrm{~Hz}$ generate an average peak voltage output value of $76 \mathrm{mV}$ [81]. Additional, a piezoelectric unit based on two outermost polydimethylsiloxane (PDMS) layers, two aluminum electrodes and a PVDF fibrous mat in center reached a piezoelectric sensitivity of 178 $\mathrm{mV} / \mathrm{kPa}$ [82].

Regarding inorganic piezoelectrics, lead zirconate titanate, PZT, is among the most used for applications including sensors and actuators, non-volatile ferroelectric memory devices, micro-electromechanical systems (MEMS) and nanogenerators [83]. It shows, in general, higher performance than organic piezoelectric [83]. Nevertheless, synthetized bulk PZT ceramics are brittle materials and there is a growing demand for flexible PZT nanofiber materials [84], being electrospinning one of the most used methods to fabricate long length fibers with uniform diameter and varied composition [85]. 


\subsection{Energy harvesting based on electrospun nanofibers}

With the reduction of fossil fuels and the increasing demand of sustainable energy for economic development, it is essential to develop renewable energy technologies to sustain the economic evolution. Capturing residual and typically wasted energy available in the environment emerges as an interesting possibility to power specific devices. The so called energy harvesting involves collecting energy from the environment or devices, including vibrations, heat, and electromagnetic waves, among others, and converting them into electrical energy [12].

Due to their unique mechanical, electrical and active properties, electrospun nanostructured materials are attractive for the development of active energy harvesters such as piezoelectrics, photovoltaics, hydrogen energy generators, and fuel cells [86].

As for their application in solar cells, electrospun $\mathrm{TiO}_{2} \mathrm{NF}$ have demonstrated high photoelectric conversion efficiency due to effective charge separation and transport and the maximum light absorption, which is mainly attributed to high specific surface areas and high porosity [87]. Further, electrodes prepared by electrospun $\mathrm{Gd}_{2} \mathrm{MSbO}_{7} \mathrm{NFs}_{\text {has }}$ demonstrated high specific capacitance and improved cycling stability due to its unique fiber morphology, including large SVR and small diameter [88].

Additionally, $\mathrm{TiO}_{2}$ electrospun NF exhibit high surface areas, enhanced crystallinity and photocatalytic activity (PCA) for hydrogen evolution when compared to those made by hydrothermal synthesis [86]. Ce-doped $\mathrm{BaTiO}_{3}$ nanofibers-based harvesters were prepared by sol-gel combined with electrospinning method. The reported delivered power of the energy harvesting device was optimized to $14.37 \mu \mathrm{W}$ with a load resistance of 100 $\mathrm{M} \Omega$, when the $\mathrm{Ce} / \mathrm{Ba}$ atomic ratio was $0.6 \%$.

Regarding polymer-based fibers for piezoelectric energy harvesting [89] (PVDF-TrFE) nanofibers have been developed with the diameter ranging from 1000 to sub-100 nm and $26 \mathrm{nW}$ power output.

Aiming biocompatibility and biodegradability on the developed energy harvesters, poly(1lactic acid) (PLLA) piezoelectric nanofibers were developed, demonstrating that an opencircuit voltage and short-circuit current with a strain deformation angle $28.9^{\circ}$ could reach $0.55 \mathrm{~V}$ and $230 \mathrm{pA}$ [90]. The optimized prototype harvester worked well for harvesting human joint motion energy with a maximum peak power $19.5 \mathrm{nW}$.

On composites, barium titanate nanoparticles embedded in polyurethane and PVDF-TrFE nanofibers were developed. The resulting nanofibers shown a high stretchability $(40 \%)$ 
and high mechanical durability (9000 stretching cycles at 30\% strain), producing a peak open circuit voltage $\left(\mathrm{V}_{\mathrm{oc}}\right)$ and short circuit current $\left(\mathrm{I}_{\mathrm{sc}}\right)$ of $9.3 \mathrm{~V}$ and $189 \mathrm{nA}$, respectively. When placed over the knee cap of a subject when walking the harvester generated a maximum $\mathrm{V}_{\mathrm{oc}}$ of $10.1 \mathrm{~V}$.

Different contents of PZN-PZT nanoparticles of $\approx 54 \mathrm{~nm}$ were embedded into a matrix of PVDF-TrFE by electrospinning[91], reporting a $3.4 \mathrm{~V}$ output voltage and $240 \mathrm{nA}$ output current for $20 \mathrm{vol} \%$ nanoparticles-incorporated into the polymer matrix.

Layers of $\mathrm{MoS}_{2}$ were grown on cellulose paper by hydrothermal method followed by the deposition of in situ poled PVDF nanofibers that generated peak voltage of $50 \mathrm{~V}$, short circuit current of $30 \mathrm{nA}$ and average power of $0.18 \mathrm{~mW} / \mathrm{cm}^{2}$ [92].

There are more than two hundred piezoelectric materials that can be used for energy harvesting including quartz, barium titanate, lead titanate (PT), cadmium sulphide (CdS), lead zirconate titanate, lead lanthanum zirconate titanate (PLZT), lead magnesium niobate $\left(\mathrm{MgNb}_{2} \mathrm{O}_{9} \mathrm{~Pb}_{3}\right)$ polyvinylidene fluoride, and polyvinyl fluoride (PVF), among others [93], allowing a large variety of functional responses and tailored processability, including, for some of them, in the form of electrospun fibers.

\section{Piezoelectric Materials}

The materials with piezoresistive properties- materials that change their geometry with applied voltage and vice-versa- can be synthetic or natural. Synthetic materials are the most used in commercial applications due their higher figures of merit in terms of functional response.

Materials with piezoelectric properties can be divided into different categories: single crystals, ceramics, polymer and polymer composites (usually ceramics embedded into polymer matrices).

Most energy harvesting applications use piezoelectric single-crystals and ceramics, or composites materials, as polymers show lower piezoelectric properties.

On the other hand, polymers can sustain higher strains due to their intrinsic flexibility and can be processed in a larger variety of forms and shapes by low temperature methods. Ceramics and single-crystals are too rigid and brittle.

\subsection{Piezoelectricity in polymers}

There are different piezoelectric polymer categories: bulk, composites and charged polymers (Figure 9) [21]. The first category of piezoelectric polymers are the solid films 
with intrinsic piezoelectric properties [21]; the second category, polymer composites, are based on polymers reinforced with piezoelectric micro- and nanomaterials (mostly ceramics materials) [21]. These materials make use of the mechanical properties of polymers (flexibility or stretchability, low density, etc) and the high dielectric and piezoelectric properties of the fillers. Finally, the third category is related to voided charged polymers, which electroactive response has a different origin: in these polymers, gas voids are developed into the polymer and their surfaces are electrically charged to obtain internal dipoles.

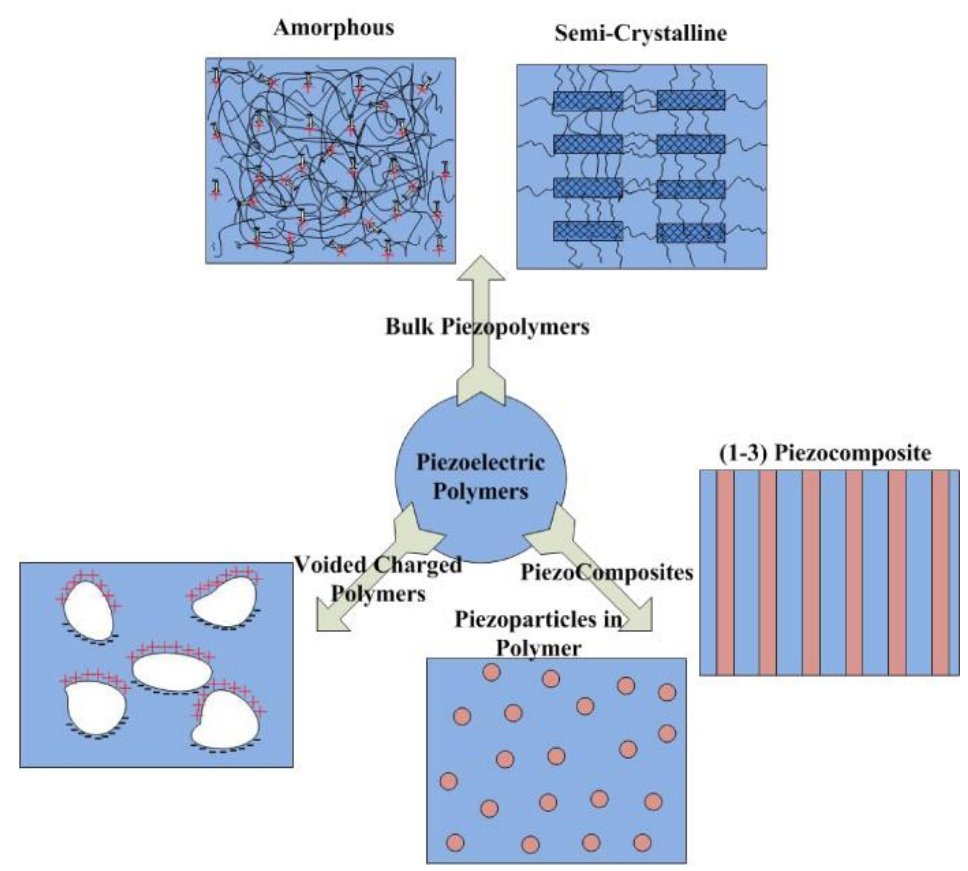

Figure 8- Schematic representation of piezoelectric polymer types: bulk piezopolymers than can be divided into amorphous dipolar polymers and semi-crystalline polymers; polymer composites, with examples of fillers in the form of particles or columns within polymer (known as 0-3 and 1-3 connectivity, respectively); voided charged polymers, with surface charged air voids within the polymer [21].

Bulk piezoelectric polymers mainly consist on amorphous or semi-crystalline polymers. These polymers must present molecular dipoles and these dipoles must be reoriented, by poling, within the bulk material and kept in their preferred orientation state [21].

Piezoelectric composites are developed using a polymer reinforced with piezoelectric inorganic particles. The polymer matrix can be also piezoelectric, increasing the coupling 
factor and dielectric properties of the composite [21]. The manufacturing of the polymer composites can lead to randomly oriented or orientated fillers (Figure 9).

Voided charged polymers are characterized by larger dielectric responses and $d_{33}$ larger than $20000 \mathrm{pC} / \mathrm{N}$, even larger than ceramics materials [21]. This structure was first presented in the early 1960s (Figure 10) [94], based on the theoretical concept of embedding air voids within the polymer and poling the material to create internal charging in torn of the voids. By applied a large electric field in the polymer, the gas molecules within the voids get ionized and opposite charges are implanted on each side of the voids [94], leading to artificial dipoles which responds like a piezoelectric material to an external electric field or mechanical stimulus [21].

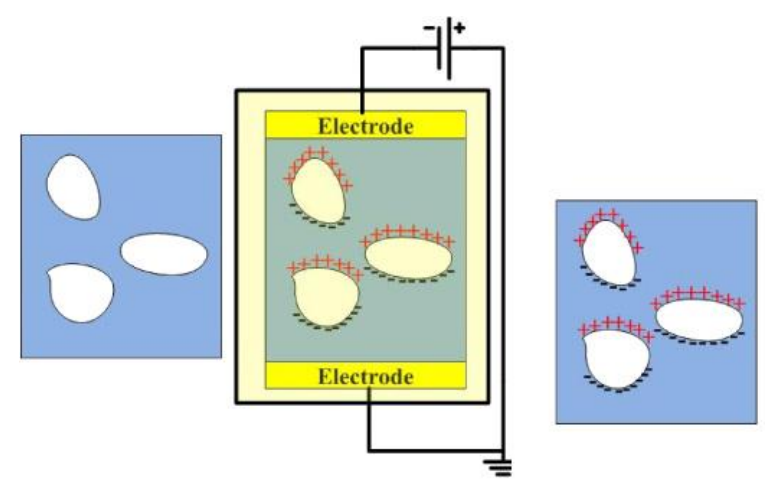

Figure 9- Illustration of piezoelectricity in voided charged polymers: voided polymer before charging (left), poling process for form the trapped dipoles (centre) and charged polymer (right). Adapted from [21].

\subsubsection{Main properties of piezoelectric polymers}

Pioneer works in the 60s by Kawai in piezoelectric polymers led to strong research activity in poly(vinylidene fluoride) and respective copolymers [95]. These electroactive polymers are the most interesting ones used in applications including sensors or actuators, energy harvesting or biomedical applications [95].

Polymers present as a main advantage their mechanical properties and as the main disadvantage the low piezoelectric coefficients (usually $d_{33} \leq 30 \mathrm{pC} / \mathrm{N}$ ). However, their piezoelectric stress constant is higher when compared to other piezoelectric materials, being suitable for sensors devices. Other relevant advantages of polymers are their relatively low-cost processing, lightweight (low density), low dielectric constant and high dielectric breakdown. 


\subsubsection{Amorphous piezoelectric polymers}

Amorphous polymers show lower piezoelectric properties when compared to semicrystalline materials. The piezoelectric effect in amorphous polymers is based on the fact that the polarization is rather in a quasi-stable state due to the freezing-in of molecular dipoles and, therefore, it is not in a state of thermal equilibrium [18]. Thus, it is generally required the application of an external electric field in order reorient the molecular dipoles of the amorphous polymer. This polarization procedure must be applied above the glass temperature transition, where the dipoles have larger mobility [96].

Piezoelectric amorphous polymers include poly(acrylonitrile) (PAN), poly(vinylidene cyanide-vinyl acetate) (PVDCN/VAc), poly(phenyl ether nitrile) (PPEN), and poly(1bici- clobutanecarbonitrile). The most studied of these amorphous polymers is vinylidene cyanide and vinyl acetate copolymer, which presents suitable piezoelectric response and large dielectric relaxation strengths [18].

The remaining amorphous polymers with piezoelectric properties present lower properties than semi-crystalline polymers [96]. PVDCN/VAc and PAN present a similar structure and the largest remnant polarization and piezoelectric stress when compared to other polymers [96].

\subsubsection{Semi-crystalline polymers}

Semi-crystalline polymers present interesting piezoelectric properties and several of them are already used in commercial applications.

\subsubsection{PVDF and PVDF copolymers}

The semi-crystalline polymer most studied and used in device application is poly(vinylidene fluoride) and its co-polymers, being still the electroactive polymers with the overall best performance $[14,21]$.

PVDF is synthesized by the polymerization of $\mathrm{CH}_{2}-\mathrm{CF}_{2}$, the monomer of PVDF showing a high electrical dipole moment of $8 \times 10^{-30} \mathrm{C} \times \mathrm{m}$. It can present different crystalline phases, the main ones being the non-polar $\alpha$ phase (TGTG' -trans-gauche-trans-gaucheconformation) and the polar $\beta$-phase (TTT -all trans- planar zigzag conformation) [14, 97] (Figure 10). The highest piezoelectric response, ranging from -24 to $-34 \mathrm{pC} / \mathrm{N}[14$, $21]$ is obtained in the $\beta$-phase. Other crystalline phases of PVDF include the $\delta$ (TGTG' trans-gauche-trans-gauche), the $\varepsilon$ and the $\gamma\left(\mathrm{T}_{3} \mathrm{GT}_{3} \mathrm{G}^{\prime}\right)$ phases. The degree of crystallinity 
of PVDF ranges typically between 50 and $60 \%$ and the glass transition temperature is around $-35^{\circ} \mathrm{C}[98]$.

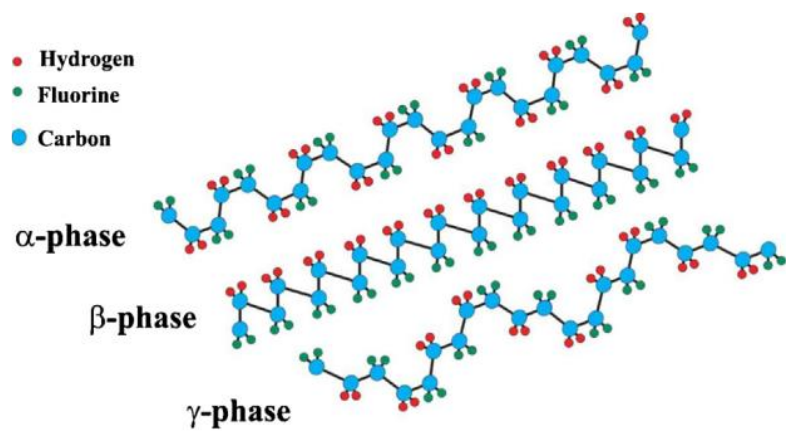

Figure 10- Schematic representation of the chain conformation for the $\alpha, \beta$ and $\gamma$ phases of PVDF.

PVDF in the polar $\beta$-phase can be obtained by mechanical deformation of $\alpha$-PVDF in order to obtain orientation of the molecular chains [18], electrospinning [60], or by developing composites with $\mathrm{BaTiO}_{3}$ [99], organic clays [100], ionic liquids [101], or magnetic fillers [102], among others.

Copolymers and terpolymer of PVDF have been developed to tailor the electroactive response of the polymer [103]. Poly(vinylidene fluoride-trifluoroethylene) (PVDF-TrFE) is synthesized through free radical polymerization of the two monomers [18], it shows lower ferroelectric to paraelectric transition temperature than PVDF, the transition temperature decreasing with increasing TrFE contents in the copolymer [103]. The main advantage of PVDF-TrFE is that for certain TrFE contents, it crystallizes directly in the electroactive phase, either by processing from solvent of from the melt. Further, PVDFTrFE shows larger electroactive response, $d_{33}$ and $k_{33}$, than PVDF [21].

Another copolymers include poly(vinylidene fluoride-co-hexafluoropropene), (PVDFHFP) [104], poly(vinylidene fluoride-chloride trifluoride ethylene) (PVDF-CTFE) [105] and poly(vinylidene fluoride-bromotrifluoroethylene (PVDF-BTFE) [106, 107].

\subsubsection{Other semicrystalline piezoelectric polymers}

Thermoset polymers such as polyurea, is constituted by hard and soft domains that present microphase separation between them. Polyurea presents excellent overall properties, including stretchability, impact mitigation, chemical resistance and a wide range of 
operating temperatures. Polyurea films are usually produced by vapor deposition polymerization in vacuum, exhibiting a piezoelectric constant of $\mathrm{d}_{31} \approx 10 \mathrm{pC} / \mathrm{N}$, which is stable up to $200{ }^{\circ} \mathrm{C}[108]$.

Other semi-crystalline polymers with excellent piezoelectric response in a wide temperature range are polyamides (known as odd-numbered nylons, including nylon-5, nylon-7, and nylon-11). The odd nylons present a monomer unit consisting in even numbers of methylene groups and one amide group with a dipole moment [108]. The amide dipoles align synergistically for the odd-numbered monomer, resulting in a net dipole moment of 4.9 debye and a piezoelectric constant above the glass transition temperature of $\mathrm{d}_{31} \approx 17 \mathrm{pC} / \mathrm{N}$.

In addition to these polymers, electroactive biopolymers are a class of materials with applications in the biomedical area. Biopolymers show piezoelectric properties lower than the other polymer materials (less than $\approx 8 \mathrm{pC} / \mathrm{N}$ ), being the piezoelectric effect mostly attributed to internal rotation of polar atomic groups linked to asymmetrical carbon atoms. Biopolymers include natural and synthetic ones, natural ones showing poor mechanical properties and difficult processing. Natural biopolymer include DNA oriented films, collagen, polypeptides like poly $(\gamma$-methylglutamate $)$ and poly( $\gamma$-benzyl-L-glutamate $)$ poly(a-hydroxy acid)s family and chitin [18]. Synthetic biopolymers include the poly(ahydroxy acid)s family and its copolymers $[18,109]$.

\subsubsection{Polymer-based composites}

Piezoelectric composites are typically fabricated based on a polymer matrix, due their mechanical properties, and ceramic fillers with high dielectric response. Further, the polymer can be also piezoelectric allowing to improve the piezoelectric overall properties of the composite.

One of the key parameters in a composite is its dimensional connectivity, exemplified in Figure 11 for the 0-3 and 1-3 connectivities, the most used in device applications. A composite with m-n connectivity has its piezoelectric phase connected in $\mathrm{n}$ dimensions for the polymer phase and in $\mathrm{m}$ dimensions for the filler [18]. 


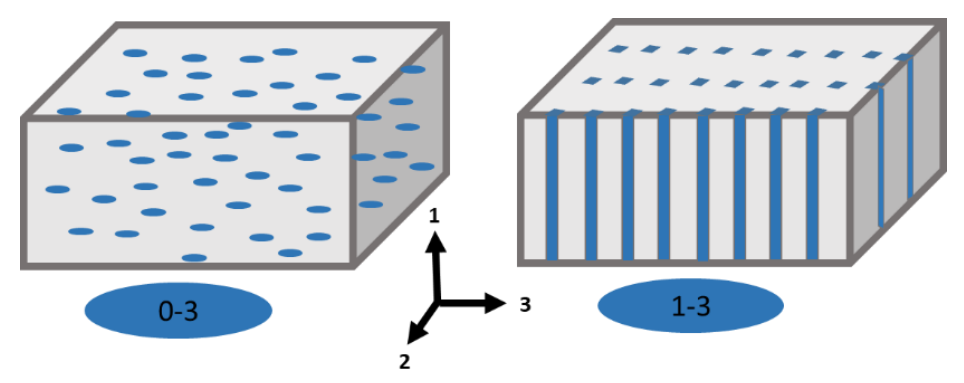

Figure 11- Piezoelectric composite material structures with 0-3 and 1-3 connectivity with polymer as matrix (grey) and dielectric fillers (blue spheres and bars).

The 0-3 connectivity is the most commonly used, and the challenger is obtaining larger fillers contents in a polymeric matrix without losing mechanical properties. Homogeneous filler dispersion is the key parameter in this type of composites. The two most common methods to produce 1-3 piezoelectric materials are dice-and-fill and laminate-and-cut procedures [110].

Using two (or more) materials for the development of composites present advantages and disadvantages. On the one hand, there is the low-cost, lightweight and flexibility of the polymers combined with the higher dielectric properties of the ceramics or single crystal materials; on the other hand, the thermal and chemical stability (for device applications) can be a limitation of composites.

Typical example of the ceramics used in polymer-based piezoelectric composites are $\mathrm{BaTiO}_{3}, \mathrm{PZT}$ and PMN-PT $[18,111]$. These composites have been largely applied as ultrasonic transducer in applications [18].

Within polymer, elastomers and thermoplastics are widely used in piezoelectric composites, due mechanical and dielectric properties [112].

\subsubsection{Piezoelectric ceramics and single crystals}

Piezoelectric materials with larger coefficients are ceramics and single crystals and can be natural or man-made. One of the most abundant minerals on earth and a common natural piezoelectric material is quartz $\left(\mathrm{SiO}_{2}\right)$. Natural piezoelectric materials can be divided into two groups: minerals and organic materials. Quartz and Rochelle salt are the representative or the first group, whereas bone and wood are the most known of the organic group. 
In the last few years there are increasing studies in novel nanostructures including nanoparticles, nanorods, nanotubes, nanowires or nanoplates which are expected to improve the piezoelectric properties of materials.

\subsubsection{Piezoelectric ceramics}

Piezoelectric ceramics are the most used materials for practical applications. Ferroelectric oxides for the development of piezoelectric ceramics are classified into perovskite-type, tungsten bronze-type, and bismuth layer-structured compounds.

Barium titanate and lead zinc titanate present high piezo- and dielectric properties and be further improved by using specific dopants. Moreover, the $\mathrm{PZT}$ and $\mathrm{BaTiO}_{3}$ show high electromechanical coupling factor and display large bandwidth and sensitivity [18].

The structure of both ceramics is based on an $\mathrm{ABO}_{3}$ perovskite structure, as shown in Figure 12. Perovskite $\mathrm{ABO}_{3}$ oxides structurally consist on $\left(\begin{array}{lll}1 & 0 & 0\end{array}\right)$ layers of $\mathrm{AO}$ and $\mathrm{BO}_{2}$ with corner-sharing oxygen octahedra linked together in a cubic array with particular cations $(\mathrm{Ti}, \mathrm{Zr}, \mathrm{Sn}, \mathrm{Nb})$ occupying the central octahedral B-site, and larger cations $(\mathrm{Pb}$, $\mathrm{Ba}, \mathrm{Sr}, \mathrm{Ca}, \mathrm{Na}$ ) filling the interstices between octahedra in the larger A-site.
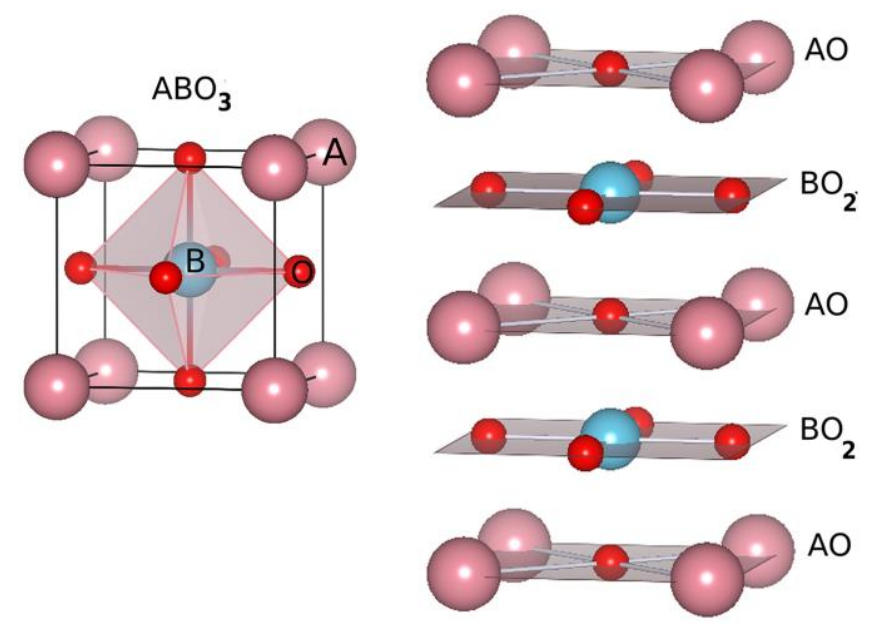

Figure 12- Left panel: the perovskite structure of general formula $\mathrm{ABO}_{3}$. Right panel: the layered stacking of $\mathrm{AO}$ and $\mathrm{BO}_{2}$ planes in a perovskite structure. Adapted from [113].

The perovskite structures can be divided into three classes: $\mathrm{A}^{\mathrm{I}} \mathrm{B}^{\mathrm{V}} \mathrm{O}_{3}, \mathrm{~A}^{\mathrm{II}} \mathrm{B}^{\mathrm{IV}} \mathrm{O}_{3}$, and $\mathrm{A}^{\mathrm{III}} \mathrm{B}^{\mathrm{III}} \mathrm{O}_{3}$ where the Roman nomenclature represents the chemical valence of the cations.

PZT ceramic is a representative piezoelectric material used in microelectronic devices due its large piezoelectric coefficients $\left(\mathrm{d}_{33} \leq 1000 \mathrm{pC} / \mathrm{N}\right)$ [114]. Zirconate $(\mathrm{Zr})$ is essential 
in the crystalline symmetry of PZT, that presents tetragonal ferroelectric phase with a perovskite structure. The ratio between $\mathrm{Zr} / \mathrm{Ti}$ near 52/48 leads to a structural change from tetragonal to a rhombohedral phase [115]. The morphologic phase boundary (MPB) delimits both structural phases and, in the limit, both tetragonal and rhombohedral phases coexisting (Figure 14) [115]. The MPB state allows the maximum domain reorientation during poling, with larger remnant polarization in the materials [18]. By varying zirconate and titanate content in the PZT ceramic, $\mathrm{Pb}\left(\mathrm{Zr}_{1-\mathrm{x}} \mathrm{Ti}_{\mathrm{x}}\right) \mathrm{O}_{3}$ can be antiferroelectric (at 230 $\left.{ }^{\circ} \mathrm{C}\right)\left(\mathrm{PbZrO}_{3}\right)$ and ferroelectric $\left(\mathrm{PbTiO}_{3}\right)$. As mentioned above, the $\mathrm{Zr} / \mathrm{Ti}$ ratio of 52/48 leads to the larger dielectric properties (Figure 13) and it is thermally stable, with Curie temperature $\left(\mathrm{T}_{C}\right)$ near $390^{\circ} \mathrm{C}$ [116]. Lead zirconate titanate ceramic can be doped with different ions (donor, acceptor or isovalent). Donor or acceptor doped materials are known as "soft" or "hard" PZT. Odd number in PZT, as PZT-5, creates Pb vacancies that allow domain motion and are used in high sensitivity applications as hydrophones or loudspeakers [116]. Even number in PZT, as PZT-8, as the oxygen vacancies restrict the motion of the domain walls, and are used in high-power devices such as sonars or ultrasonic transducers [116]. Isovalent doping changes the ions of the same valence and may result in a decrease of the Curie temperature and an increase of the dielectric constant [116].

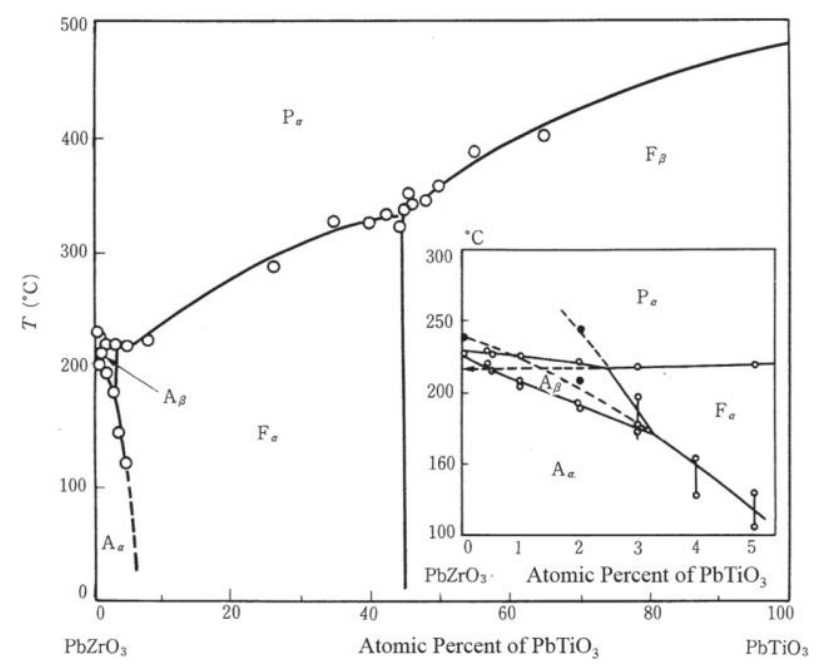

Figure 13- Phase diagram for the $\mathrm{Pb}(\mathrm{Zr}, \mathrm{Ti}) \mathrm{O}_{3}$ solid solution system [117].

Lanthanum was found to improve the piezo- and dielectric properties of the ceramics in ternary material. PLZT ternary ceramics have been investigated for different lanthanum contents and $\mathrm{Zr} / \mathrm{Ti}$ ratios, which exhibits a variety of ferroic phases and cover all aspects 
of piezo-,pyro-, and ferroelectric ceramic properties [118]. Compared to undoped PZT, PLZT present larger piezo- and dielectric values, but however, the thermal properties (such as the Curie temperature) decreases with increasing lanthanum in the ternary ceramic [119].

Other critical property of PZT (or ternary ceramics derived) is toxicity of lead, and a leadfree line of investigation continues increasing to discover environmental friendly ceramics [18]. Among these materials, some based on $\mathrm{BaTiO}_{3}$ perovskite-structured piezoelectrics, are included $\left(\mathrm{Bi}_{1 / 2} \mathrm{Na}_{1 / 2}\right) \mathrm{TiO}_{3},\left(\mathrm{Bi}_{1 / 2} \mathrm{~K}_{1 / 2}\right) \mathrm{TiO}_{3}, \mathrm{KNbO}_{3}$, or $(\mathrm{K}, \mathrm{Na}) \mathrm{NbO}_{3}$, and their solid solutions have been actively studied as candidates for new lead-free piezoelectric ceramics [18]. Although environment friendly and showing suitable piezoelectric properties, up to now, no lead-free ceramic materials present better piezoelectric properties than PZT based ceramics [18].

Barium titanate, similarly with PZT, shows interesting overall properties, with large number of applications in commercial devices. The most relevant applications include capacitors, embedded capacitance in printed circuit boards, underwater transducers (sonars), thermistors with positive temperature coefficient of resistivity and electroluminescent panels [119]. The main properties of $\mathrm{BaTiO}_{3}$ are the higher electromechanical coupling factor, $\mathrm{k}_{33} \approx 0.50$ and a piezoelectric strain constant $\mathrm{d}_{33} \approx 190$ $\mathrm{pC} / \mathrm{N}$. However, the Curie temperature is $130^{\circ} \mathrm{C}$, which is low for $\mathrm{c}$ applications. Dopants as lead and calcium have been used in barium titanate ceramic to stabilize the tetragonal phase over a wider temperature range.

Other materials used as dopant in $\mathrm{BaTiO}_{3}$ are sodium and potassium and the ternary ceramic shows improved piezoelectric properties, but low Curie temperature.

In addition to PZT and $\mathrm{BaTiO}_{3}$, bismuth sodium titanate, $\left(\mathrm{Bi}_{1 / 2} \mathrm{Na}_{1 / 2}\right) \mathrm{TiO}_{3}, \mathrm{BNT}$, is a ferroelectric perovskite with high Curie temperature $\left(\approx 290^{\circ} \mathrm{C}\right)$ exhibiting large remnant polarization and high piezoelectric performance $\left(\mathrm{d}_{33} \approx 170\right.$ to $\left.215 \mathrm{pC} / \mathrm{N}\right)[120]$ when compared to other lead-free piezoelectric ceramics [121]. Doped BNT with niobium sodium oxide $\left(\mathrm{NaNbO}_{3}\right)$ [121] improves the overall properties and processability of the ceramic, with the piezoelectric constant reaching $\mathrm{d}_{33}>100 \mathrm{pC} / \mathrm{N}$ [122].

Similar structure to the BNT, but replacing sodium by potassium titanate, $\left(\mathrm{Bi}_{1 / 2} \mathrm{~K}_{1 / 2}\right) \mathrm{TiO}_{3}$, BKT, is a lead-free ceramic with perovskite structure of tetragonal symmetry and a high Curie temperature of approximately $380{ }^{\circ} \mathrm{C}[123,124]$. Ternary ceramics materials combining the $\mathrm{BKT}, \mathrm{BNT}$ and $\mathrm{BaTiO} 3$ present interesting properties and continue to be investigated in view optimizing the overall properties of the three ceramics in one 
material. In this context, (1-x) $\mathrm{BaTiO}_{3}-\mathrm{xBKT}$, show larger piezoelectric properties, with piezoelectric constant $d_{31} \approx 350 \mathrm{pC} / \mathrm{N}$ and $d_{33} \approx 450 \mathrm{pC} / \mathrm{N}$ [124].

Also based in a similar perovskite structure $\left(\mathrm{ABO}_{3}\right)$, an alternative lead-free ceramic material is potassium niobate $\left(\mathrm{KNbO}_{3}\right.$ or $\left.\mathrm{KN}\right)$. Doped with sodium, potassium-sodium ceramic, $\mathrm{KNN}$, can show a high Curie temperature, near $T_{C}=430^{\circ} \mathrm{C}$, and the piezoelectric properties of the family of the KNN lead-free ceramic can reach values up to $d_{33} \approx 500$ $\mathrm{pC} / \mathrm{N}[115,122,124] . \mathrm{KNN}$ is considered one of the most promising alternatives to leadcontaining ceramics, showing high Curie temperature and electromechanical coupling factor, strong ferroelectricity and a dielectric constant of $\varepsilon^{\prime} \approx 500$. [18, 122]. KNN materials can be manufactured as nanocrystals improving their properties [115]. Some examples of piezoelectric ceramics based on KNN is KNN-potassium cooper titanatemanganese $\left(\mathrm{K}_{0.5} \mathrm{Na}_{0.5} \mathrm{NbO}_{3}-\mathrm{K}_{5.4} \mathrm{Cu}_{1.3} \mathrm{Ta}_{10} \mathrm{O}_{29}-\mathrm{MnO}_{2}\right.$ or $\left.\mathrm{KNN}-\mathrm{KCT}-\mathrm{Mn}\right)$, which shows good piezoelectric properties $\left(d_{33} \approx 90\right.$ and $\varepsilon^{\prime} \approx 300$ [18]) for commercial applications [115]. Among the different materials used as dopants for KNN, copper oxide improves the piezoelectric properties due to improved poling efficiency of the ceramic.

With interesting properties and being a lead-free ceramic, zinc oxide $(\mathrm{ZnO})$ presents excellent mechanical properties, piezoelectric response ( $d_{33} \approx 12.4$ and $\varepsilon \approx 10.9$ [18]) and optical $[125,126]$. Another characteristic of $\mathrm{ZnO}$ is its simple manufacturing in the form of nanoscale fibres, wires and particles [126].

\subsubsection{Piezoelectric single crystals}

Single crystals were the first discovered piezoelectric material. Quartz $\left(\mathrm{SiO}_{2}\right)$ and lithium niobite $\left(\mathrm{LiNbO}_{3}\right)$ are the most commercially available single crystals. Quartz is silicon dioxide crystalized in six-sided prisms, with piezoelectric properties when in $\alpha$-phase and with a Curie temperature of $573{ }^{\circ} \mathrm{C}$. Lithium niobite, with chemical formula of $\mathrm{ABO}_{3}$ and a Curie temperature of $1200^{\circ} \mathrm{C}$ is used in high-frequency devices and for high temperature applications.

Rochelle salt - $\mathrm{NaKC}_{4} \mathrm{H}_{4} \mathrm{O}_{6}-4 \mathrm{H}_{2} \mathrm{O}$ - is sodium potassium tartrate tetrahydrate shows a large piezoelectric behaviour $\left(\varepsilon^{\prime}>100\right.$ [127]) under very specific temperature $\left(-18\right.$ and $\left.24{ }^{\circ} \mathrm{C}\right)$ and humidity conditions [128], limiting its applicability.

Lead magnesium niobite $\left(\mathrm{Pb}\left(\mathrm{Mg}_{1 / 3} \mathrm{Nb}_{2 / 3}\right) \mathrm{O}_{3}\right.$ or $\left.\mathrm{PMN}\right)$ exhibits high dielectric constant that can reach near 30000 [18].

Lead zinc niobite $\left(\mathrm{Pb}\left(\mathrm{Zn}_{1 / 3} \mathrm{Nb}_{2 / 3}\right) \mathrm{O}_{3}\right.$ or $\left.\mathrm{PZN}\right)$ ferroelectric single crystals present excellent dielectric properties to be used in sensor and actuator applications. Near the 
morphologic phase boundary (MPB) at room conditions shows large piezo- and dielectric constants as well good electromechanical coupling coefficient [129].

Lead titanate doping lead magnesium niobite (PMN-PT) is an interesting single crystal family, with good dielectric and piezoelectric properties because of enhanced polarizability arising from the coupling near the MPB of the crystal. These family of crystal have dielectric properties similar to PZT ceramic but the Curie temperature is lower, near $130{ }^{\circ} \mathrm{C}$ [98]. Ternary system based on PMN-PT have been developed to overcome their intrinsic limitations, improving the mechanical and thermal properties [98].

Aluminium nitrite $(\mathrm{AlN})$ and Lithium tantalite $\left(\mathrm{LiTaO}_{3}\right)$ present good overall properties for applications. AlN thin films show a dielectric constant near $\varepsilon^{\prime} \approx 10$ [130] and $d_{33} \approx 5$ [131] and can be used in surface acoustic wave applications. Compared to $\mathrm{AlN}, \mathrm{LiTaO}_{3}$ shows higher dielectric and piezoelectric constant, $\varepsilon^{\prime} \approx 44-47$ and $d_{33} \approx 14.6$, respectively [132], and has been applied in pyroelectric devices [132].

A summary of the main properties of the single crystal and ceramics materials presented so far is found in Table 2.

Table 2- Piezoelectric materials used in energy harvesting or related applications.

\begin{tabular}{|c|c|c|c|c|c|c|}
\hline Materials & $\begin{array}{c}\text { PE charge } \\
\text { constant } \mathrm{d}_{33} \\
(\mathrm{pC} / \mathrm{N})\end{array}$ & $\begin{array}{c}\text { PE charge } \\
\text { constant d } \mathrm{d}_{31} \\
(\mathrm{pC} / \mathrm{N})\end{array}$ & $\begin{array}{l}\text { EM coupling } \\
\text { factor } k_{33}\end{array}$ & $\begin{array}{l}\text { Dielectric } \\
\text { constant } \varepsilon\end{array}$ & $T_{C}\left({ }^{\circ} \mathrm{C}\right)$ & Ref. \\
\hline \multicolumn{7}{|c|}{ Single crystals } \\
\hline Quartz & 2 & & & 4.5 & - & [133] \\
\hline LiNbO3 & 40 & - & 0.6 & 47 & 1140 & [134] \\
\hline Rochelle salt & - & 275 & 0.65 & - & $<24$ & $\begin{array}{l}{[127,} \\
128]\end{array}$ \\
\hline PMN & $<2800$ & - & $0.91-0.95$ & $>5400$ & $<150$ & {$[18]$} \\
\hline PZN & - & - & - & 9500 & - & [129] \\
\hline PMN-PT & 1620 & -760 & 0.93 & 7000 & $<155$ & $\begin{array}{l}{[98,} \\
135]\end{array}$ \\
\hline $\begin{array}{c}\text { PIN-PMN- } \\
\text { PT }\end{array}$ & 2742 & -1337 & 0.95 & 7244 & 200 & [136] \\
\hline PMN-PZT & 1530 & -718 & $0.92-0.93$ & $>4850$ & $\approx 216$ & [137] \\
\hline PZN-PT & 200 & -1075 & 0.94 & 5100 & - & [138] \\
\hline AlN & 5.1 & -2 & 0.38 & $\approx 10$ & $>2000$ & $\begin{array}{r}{[130,} \\
131]\end{array}$ \\
\hline $\mathrm{LiTaO}_{3}$ & 14.6 & 728 & 0.32 & $44-47$ & 620 & [132] \\
\hline \multicolumn{7}{|c|}{ Ceramics } \\
\hline $\mathrm{PbTiO3}$ & - & - & - & $>300$ & $\approx 490$ & [139] \\
\hline PZT & 472 & - & 0.71 & 714 & 340 & $\begin{array}{l}{[116,} \\
140]\end{array}$ \\
\hline PZT-5A & 375 & - & 0.71 & 1700 & 365 & $\begin{array}{l}{[116,} \\
140]\end{array}$ \\
\hline
\end{tabular}




\begin{tabular}{|c|c|c|c|c|c|c|}
\hline PZT-5H & 590 & - & 0.75 & 3400 & 190 & $\begin{array}{c}{[116,} \\
140]\end{array}$ \\
\hline PZT-8 & 225 & - & 0.64 & 1000 & 300 & $\begin{array}{c}{[116,} \\
140]\end{array}$ \\
\hline PLZT & - & - & 0.45 & 1800 & - & {$[119]$} \\
\hline $\mathrm{BaTiO}_{3}$ & 190 & - & 0.5 & 1700 & 115 & {$[119]$} \\
\hline $\mathrm{ZnO}$ & 12.4 & 5.0 & 0.48 & 10.9 & - & {$[18]$} \\
\hline $\mathrm{KNN}$ & 480 & - & $<0.6$ & $<500$ & 421 & {$[122]$} \\
\hline $\begin{array}{c}\text { KNN-KCT- } \\
\mathrm{Mn}\end{array}$ & 90 & -33 & 0.4 & 300 & 404 & {$[115]$} \\
\hline $\mathrm{BNT}$ & 64 & - & - & 302 & 310 & {$[120]$} \\
\hline $\mathrm{BKT}$ & 74 & - & - & - & 380 & {$[123$,} \\
\hline BNKT & 185 & - & - & 868 & 292 & {$[141]$} \\
\hline BNLT & $\approx 98$ & - & - & $\approx 550$ & $<370$ & {$[142]$} \\
\hline BNT-NN & $<80$ & - & - & $<801$ & - & {$[110]$} \\
\hline BNT-BZT & $<147$ & - & - & $<881$ & $<251$ & {$[142]$} \\
\hline
\end{tabular}

Abbreviations: PIN-PMN-PT, Lead indium niobate; PMN Lead magnesium niobate; PMN-PT, Lead magnesium niobate-lead titanate; PZN, Lead zinc niobate;PZN-PT, Lead zinc niobate-lead titanate, BKT ,Bismuth potassium titanate; BNT, Bismuth sodium titanate; KNN, Potassium-sodium niobates; KNN-KCT-Mn, KNN- potassium cooper titanate-manganese; PZT, Lead zirconate titanate

\section{Electrospun piezoelectric energy harvesting systems}

The capability of harvesting or capture the wasted surrounding energy coming from environmental sources including vehicles, industrial machines or human activity and convert it, not exclusively, into electrical energy describe the so-called energy-harvesting systems. These systems use electroactive materials as well as piezoelectric, electromagnetic or magnetostrictive methods to convert mechanical into electrical energy to enable self-powered microdevices or to supply energy to wireless sensor devices [143, 144]. Sensors for difficult access locations and in remote areas associated with the growing field of low-power electronics technology make the energy harvesting devices a good candidate for replacing batteries as power source, since the incorporation of a selfsufficient power system is an advantage in terms of low-cost maintenance. From the environmental sources, dielectric elastomers demonstrated increased efficiency for electromechanical conversion from ocean waves [145].

Energy harvesting systems based on piezoelectricity are the most widely investigated ones due to high voltage output, high power density, easy materials processing and production at different geometric scales [143]. Nowadays, the increasing interest of flexible, deformable and curved materials to a wide range of applicability is required. In this way the piezoelectric polymers which present all these characteristics allied with low density, high flexibility and high resistance to mechanical impacts make them a good 
choice for the energy harvester systems. On other hand, this class of materials present lower piezoelectric constants that the ceramic and single crystal counterparts. The most common piezoelectric polymer used is the PVDF and its copolymers due to its easy processability, high chemical resistance and flexibility.

In particular, strong advances in energy harvesting systems have been achieved based on electrospun materials.

Thus, concentric PVDF nanofibers were electrospun on a $\mathrm{Cu}$ foil in a Polyvinyl chloride (PVC) substrate and embedded in Polydimethylsiloxane (PDMS). These concentric nanofiber configurations allow the electrical energy generation from mechanical energy regardless the direction of the applied force. The device achieved a $5 \mathrm{~V}$ output voltage, $400 \mathrm{nA}$ current and an output power of $200 \mathrm{nW}$ at a load resistance of $2 \mathrm{M} \Omega$ [146]. An energy harvester system based on electrospun PVDF nanofibers deposited on a PVDF film with inner electrode of silver deposited nylon filament ( $80 \mu \mathrm{m}$ of diameter and 25 $\Omega / \mathrm{cm}$ ) reached a voltage, current and power density of $0.52 \mathrm{~V}, 18.76 \mathrm{nA}$ and 5.54 $\mu \mathrm{W} / \mathrm{cm}^{3}$, respectively. The output signals were obtained under cyclic compression of $0.02 \mathrm{MPa}$ at $1.85 \mathrm{~Hz}$ showing stability after 50000 cycles. The improved interfacial properties between the PVDF fibers and film enhanced the performance of the device [147]. Higher performance of the energy harvester system is obtained by aligned PVDF nanofibers (average diameter of $350 \pm 23 \mathrm{~nm}$, Figure 144A) due to higher content the $\beta$ phase. Kang, Won [148] deposited PVDF electrospun nanofiber onto a PET substrate with Ag electrodes, as shown in Figure 144B. The device achieved an output voltage of $1.6 \mathrm{~V}$ at a frequency of $2 \mathrm{~Hz}$.

A)

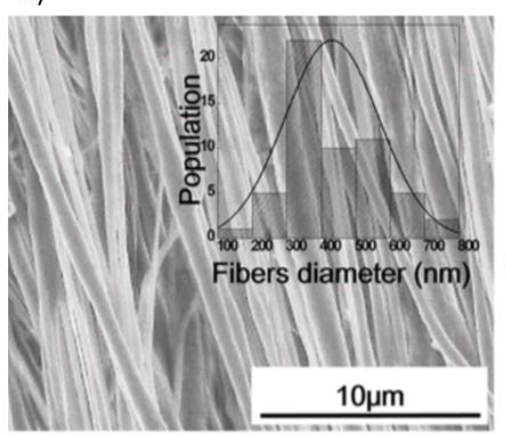

B)

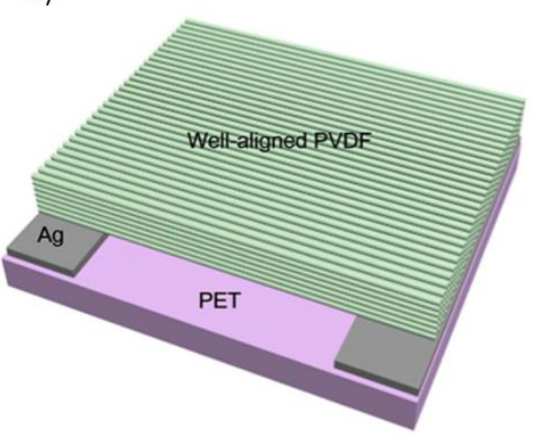

Figure 14- A) SEM image of aligned PVDF nanofibers with the diameter distribution fitted with Gaussian function; B) Illustration of the energy harvester system. Adapted from [148]. 
Aligned PVDF fibers (average diameter $\approx 1.6 \mu \mathrm{m}$ ) were deposited by a hollow cylindrical near-field electrospinning process. The oriented fibers were transferred onto a PET substrate with top and bottom $\mathrm{Cu}$ foil electrodes. An output voltage of $76 \mathrm{mV}$ and $39 \mathrm{nA}$ of current was measured with a strain of $0.05 \%$ at $7 \mathrm{~Hz}$. Schematic illustrations of the measurement systems were represented in Figure 156 [149].
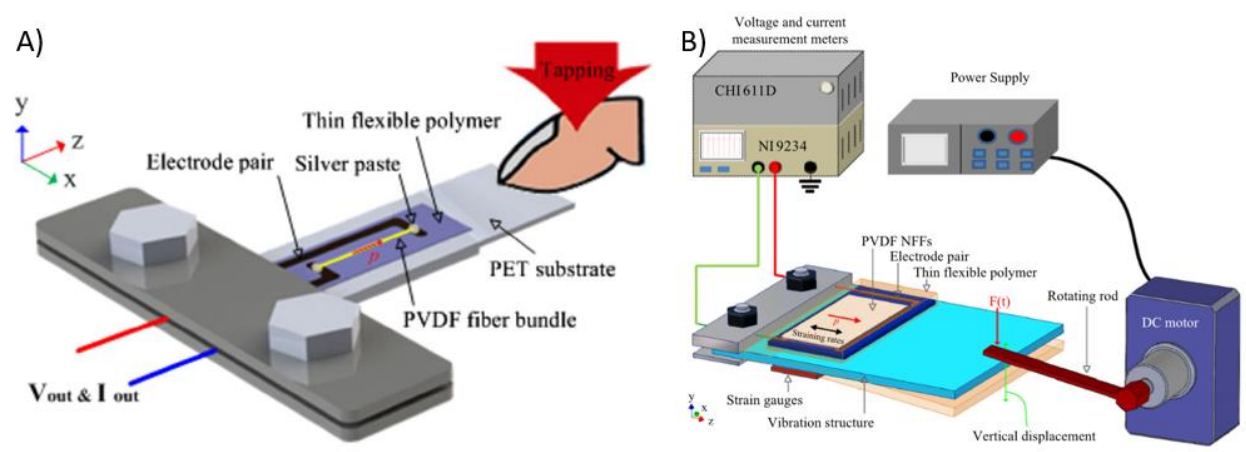

Figure 15- Schematic illustration of the tapping measurement system of the energy harvesting system; B) the vibration measurement system. Adapted from [149].

Pure PVDF-TrFE nanofibers were electrospun in a flexible plastic to develop a nanogenerator with an output voltage of $0.4 \mathrm{~V}$ to a cantilever pressure of $8 \mathrm{mN}$ at a frequency of $3 \mathrm{~Hz}$ [150]. An acoustic to electric energy conversion from a randomlyoriented electrospun PVDF-TrFE nanofiber (diameter of $240 \pm 40 \mathrm{~nm}$ and $20 \mu \mathrm{m}$ thick) sandwiched between two gold-coated PET films (110 $\mu \mathrm{m}$ of thick) generate an output voltage, current and power density of $14.5 \mathrm{~V}, 28.5 \mu \mathrm{A}$ and $306.5 \mu \mathrm{W} / \mathrm{cm}^{3}$, respectively. The maximum values were obtained under a sound pressure of $115 \mathrm{~dB}$ at $210 \mathrm{~Hz}$ [151]. A flexible energy harvesting system based on electrospun poled PVDF-TrFE fibres was sandwiched between two fibre-based electrodes electrospun based of polyurethane coated with silver nanowires and carbon nanotubes (10-30 $\mu \mathrm{m}$ of length) (triboelectric part) and packed with PDMS. The vertical structure combining the tribo- and piezoelectric method increase the performance of the device. When an external force of $4 \mathrm{~Hz}$ was applied to the triboelectric generator, an output voltage current and power density of $183 \mathrm{~V}, 1.9 \mu \mathrm{A}$ and $630 \mu \mathrm{W}$ was obtained, respectively. In case of the piezoelectric device, the values observed was $57.1 \mathrm{~V}, 2.95 \mu \mathrm{A}$ and $0.85 \mu \mathrm{W}$, respectively at a load resistance of $600 \mathrm{M} \Omega$. Due to the flexibility and sensitivity of the piezoelectric material, this device shows applicability in wearable healthcare monitoring systems as to real-time monitoring human physiological signals [152]. A polymer composite device, composed by PVDF-TrFE and 
barium titanate $\left(\mathrm{BaTiO}_{3}\right)$ ceramic fillers, was electrospun on interdigitated electrodes to study the influence of the fillers in an electrospinning process for the generation of energy. The average diameter obtained was $450 \pm 100 \mathrm{~nm}$. It was obtained higher power output for the pure PVDF fibres, with $0.02 \mu \mathrm{W}$ and $25 \mu \mathrm{W}$ for low and high mechanical deformation respectively. The performance of the device was evaluated by periodic bending tests with a maximum vertical displacement of $7 \mathrm{~mm}$ at a $1 \mathrm{M} \Omega$ load resistance. The incorporation of ceramic fillers increased the mechanical stiffness and consequently reduce the power output [153]. An energy harvesting system with cylindrical shape based on PVDF electrospun fibers with Au-coated nanowire electrodes (Figure 16) was obtained with increasing performance due to the great flexibility, stretchability, high transmittance and low sheet resistance of the electrodes. The device with $0.34 \mathrm{~cm}$ of diameter generated an output voltage and current of $4.1 \mathrm{~V}$ and $295 \mathrm{nA}$ at a strain of $0.5 \%$ and frequency of $5 \mathrm{~Hz}$, respectively. In comparation, the same device in the same conditions but without rolling generated an output voltage and current of $1.8 \mathrm{~V}$ and 140 $\mathrm{nA}$, respectively. The rolling step lead to a higher performance of the device [154].

A)

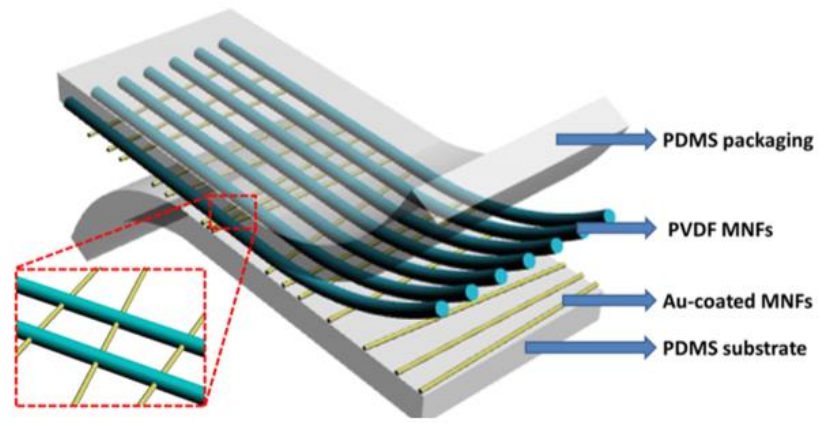

B)

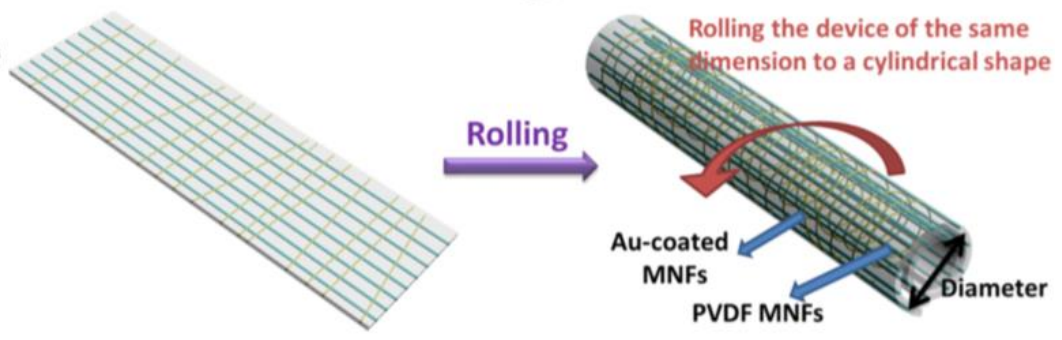

Figure 16- A) Illustration of the piezoelectric energy harvester system; B) rolling step to obtain a cylindrical-shaped energy harvester system. Adapted from [154].

The addition of multi-walled carbon nanotubes (MWCNT) in electrospun PVDF fibres increase the surface conductivity and enhance the performance of the energy harvester system. An increasing of $200 \%$ and $44.8 \%$ in output voltage and charging power is observed when compared with pure PVDF fibres. The best results were obtained for a 5 wt $\%$ MWCNT composition with a voltage of $6 \mathrm{~V}$ and capacitor charging power of 81.8 
nW [155]. An energy harvesting system based in aligned PVDF fibres with $\mathrm{BaTiO}_{3}$ nanoparticles (diameter $\approx 200 \mathrm{~nm}$ ) incorporated and embedded with PDMS obtained an output voltage of $0.48 \mathrm{~V}$ at a displacement of $6 \mathrm{~mm}$ and frequency of $0.007 \mathrm{~Hz}$ for a composition of $16 \mathrm{wt} . \%$ of $\mathrm{BaTiO}_{3}$ nanoparticles [156]. Flexible nanofiber composites of $\mathrm{BaTiO}_{3}$ dispersed in PVDF-TrFE were electrospun and embedded in a spin-coating elastomer (PDMS) to generate and storage energy during walking, as represented in Figure 17. The composite fibres presented an average diameter of $250 \mathrm{~nm}$. The elastomer provides protection for the nanofibers from mechanical damage giving a higher durability of the device. The performance was maintained over 10000 cycles and 1000 human steps as shown in Figure 17C. The energy harvesting device shows an output voltage of $25 \mathrm{~V}$ at a walking frequency of $0.6 \mathrm{~Hz}$ and a high mechanical durability under high loads (600 N) with a $15 \mathrm{wt} . \%$ of $\mathrm{BaTiO}_{3}$. This voltage can charge a $4.7 \mu \mathrm{F}$ capacitor after approximately 72 steps. The self-poled fibres lead to a high energy harvesting performance, enhancing the voltage and current outputs up to $200 \%$. This device shows low-cost and simple fabrication process, small form factor, flexibility, durability and transparency which leads to a good candidate for application in self-powered wearable electronics [157]. The same polymeric matrix was embedded with $\left(\mathrm{Na}_{0.5} \mathrm{~K}_{0.5}\right) \mathrm{NbO}_{3}(\mathrm{NKN})$ nanoparticles with $\approx 30$ $150 \mathrm{~nm}$ and a electrospun fibres were sandwiched between a ITO-coated PET substrate. The best performance with $0.98 \mathrm{~V}$ and $78 \mathrm{nA}$ for output voltage and current, respectively was obtained by a $10 \mathrm{vol} \% \mathrm{NKN}$ nanoparticles composition [158]. 
A)

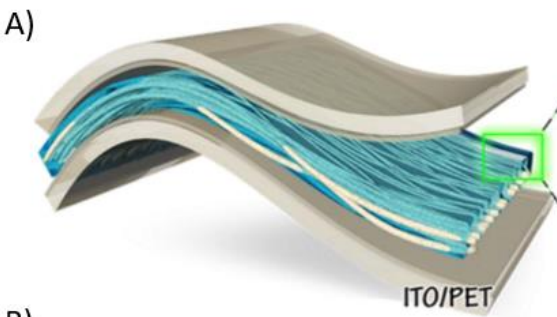

B)

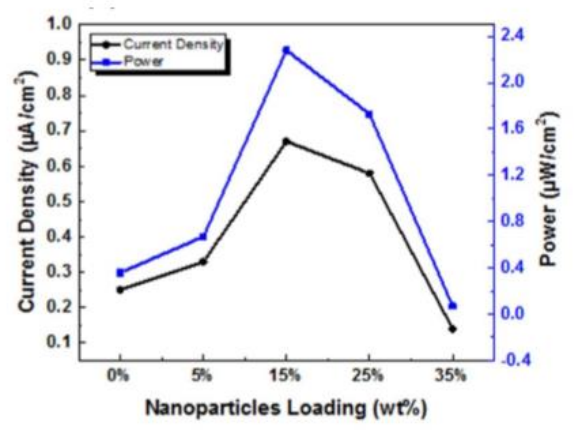

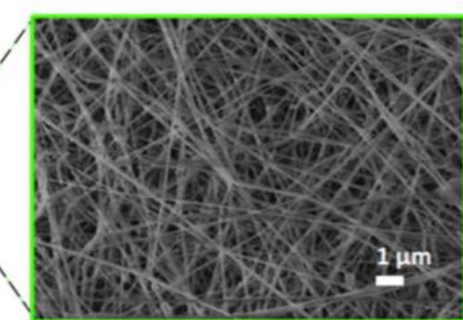

C)

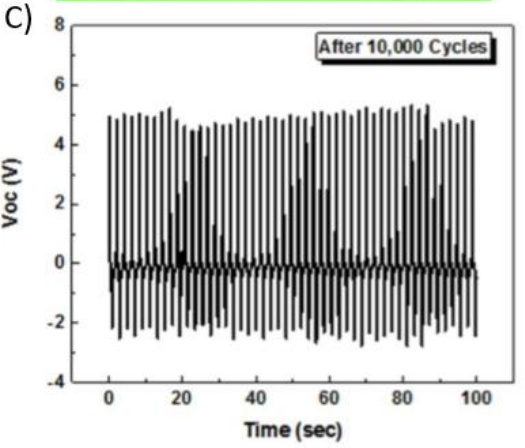

Figure 17- A) Schematic of the energy harvester system and SEM image of $35 \mathrm{wt} \%$ $\mathrm{BaTiO}_{3}$ in PVDF-TrFE nanofiber; B) output current and power density for the energy harvesting system as a function of $\mathrm{BaTiO}_{3}$ content at a force of $20 \mathrm{~N}$; C) open-circuit voltage output of a cycling tapping test of $15 \mathrm{wt} \% \mathrm{BaTiO}_{3}$ at $20 \mathrm{~N}$ after 10000 cycles. Adapted from [157].

A composition of 20 vol\% of $0.4 \mathrm{~Pb}\left(\mathrm{Zn}_{1 / 3} \mathrm{Nb}_{2 / 3}\right) \mathrm{O}_{3}-0.6 \mathrm{~Pb}\left(\mathrm{Zr}_{0.5} \mathrm{Ti}_{0.5}\right) \mathrm{O}_{3}$ (PZN-PZT) nanoparticles $(\approx 54 \mathrm{~nm}$ ) embedded in a PVDF-TrFE electrospun nanofiber sandwiched on a ITO-coated PET substrate exhibited a output voltage of $\approx 3.4 \mathrm{~V}$ and $\approx 240 \mathrm{nA}$ of current [159]. A small amount of graphene nanoplatelets ( $0.1 \mathrm{wt} \%)$ lead to a significantly increase of the $\beta$-phase, the most piezoelectric phase of PVDF, for a higher energy harvesting performance in a PVDF/graphene electrospun composite with mean diameter of $107 \pm 8$ $\mathrm{nm}$. For a pressure of $0.2 \mathrm{MPa}$ and a frequency of $1 \mathrm{~Hz}$, a composite with $0.1 \mathrm{wt} \%$ of graphene increase the open-circuit voltage and short-circuit current from $3.8 \mathrm{~V}$ to $7.9 \mathrm{~V}$ and $2 \mu \mathrm{A}$ to $4.5 \mu \mathrm{A}$, respectively. As a proof-of-concept, this sample was able to charge a $33 \mu \mathrm{F}$ capacitor to $6.5 \mathrm{~V}$ and then turn on a LED light for more than $30 \mathrm{~s}$. The incorporation of higher amount of graphene leads to a decreasing of the electrical output of the device [160].

A tri-composed energy harvesting device using electrospun $\mathrm{BaTiO}_{3}$ nanoparticles and graphene nanosheets dispersed in a polymeric matrix (PVDF) was studied. The fibers were sandwiched between aluminium foils, copper strips and PET substrates with $50 \mu \mathrm{m}$ and $150 \mu \mathrm{m}$ of thickness for top and bottom electrodes, respectively. The fibers present a 
thickness of 18-20 $\mu \mathrm{m}$. The best performance was obtained with the composition of 0.15 wt $\%$ of graphene nanosheets and $15 \mathrm{wt} \% \mathrm{BaTiO}_{3}$ nanoparticles and an open-circuit voltage of $11 \mathrm{~V}$ and an electric power of $4.1 \mu \mathrm{W}$ was obtained under a load frequency and strain of $2 \mathrm{~Hz}$ and $4 \mathrm{~mm}$, respectively. The device showed a good stability of the open-circuit voltage after 1800 cycles. The improved output is due to the synergistic contribution of both fillers to the piezoelectric enhancement of the fibers. An application in a finger pressing-releasing process was done obtaining an output voltage of $112 \mathrm{~V}$ [161].

The incorporation of the platinum nanoparticles $(\mathrm{Pt})(1.5 \mathrm{wt} \%)$ in PVDF electruspun nanofibers (diameter near $14 \mu \mathrm{m}$ ) sandwiched between a copper-nickel plate and polypropylene was proved to be a good material for small power consumer electronics. The energy harvester system reaches an output voltage, current density and power density of $30 \mathrm{~V}, 6 \mathrm{~mA} / \mathrm{cm}^{2}$ and $22 \mu \mathrm{W} / \mathrm{cm}^{2}$, respectively under a load resistance of $1 \mathrm{M} \Omega$. A good stability was also observed up to 90000 cycles [162]. Electrospun nanofiber of the copolymer PVDF-HFP embedded with silver nanoparticles (Ag) (83 nm of diameter and layer thickness $\approx 150 \pm 20 \mu \mathrm{m})$ sandwiched between two flexible electrodes achieved output voltage of $3 \mathrm{~V}$ and a current density of $0.9 \mu \mathrm{A} / \mathrm{cm}^{2}$ in a periodic pressure of $15 \mathrm{kPa}$ and frequency of $2 \mathrm{~Hz}$ [163]. The incorporation of $\mathrm{Eu}^{3+}$ to create a composite electrospun nanofiber based in $\mathrm{Eu}^{3+}$ doped PVDF-HFP/graphene, lead to higher $\beta$-phase content and an improvement in the fibre crystallinity without post-polling process. The fibres were sandwiched between two conducting $\mathrm{Ni}-\mathrm{Cu}-\mathrm{Ni}$ plated polyester fabric substrate. An output voltage and power of $9 \mathrm{~V}$ and $5.8 \mu \mathrm{W}$, respectively, was observed under fingertouch motion with $5.6 \mathrm{kPa}$ stress (Figure 18). The device was also tested under wind flows showing an open-circuit output voltage of $4.5 \mathrm{~V}$ and a power of $2.4 \mu \mathrm{W}$ for a wind velocity of $8.5 \mathrm{~m} / \mathrm{s}$ and incident angle of $45^{\circ}$ (Figure 18). An acoustic sensitivity of 11 $\mathrm{V} / \mathrm{Pa}$ for external pressure as low as $\approx 23 \mathrm{~Pa}$ of the device show the applicability of this device for sensors, including personal identification, national security and medical diagnosis [164]. 

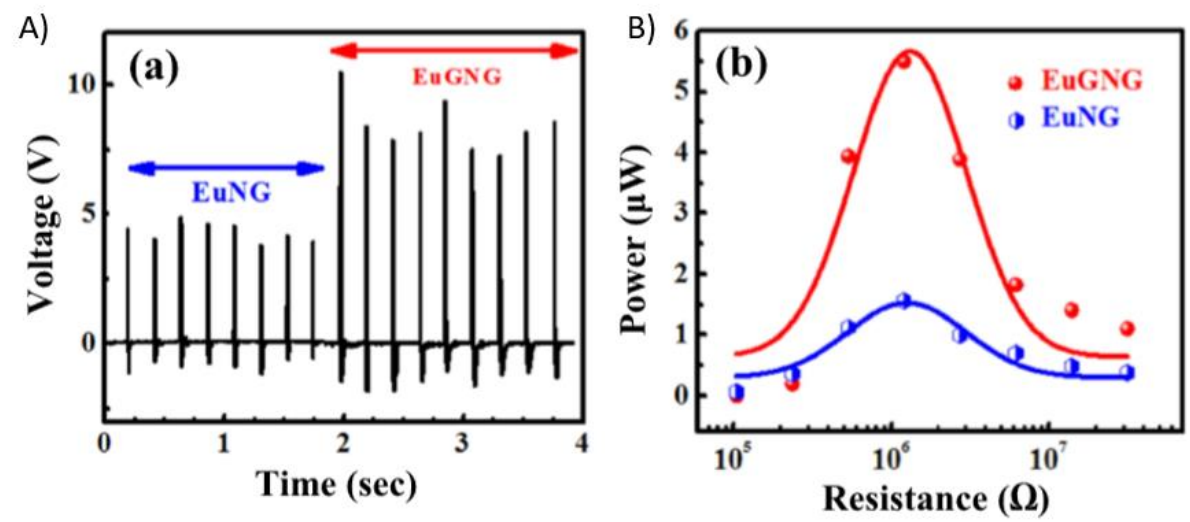

Figure 18-A) Output voltage of $\mathrm{Eu}^{3+}$ doped PVDF-HFP/graphene (EuGNG) and P(VDFHFP)/graphene (EuNG) under repeated finger-touch motion; B) Instantaneous output power as a function of load resistance. Adapted from [164].

A flexible energy harvester system based on oriented zinc sulphide $(\mathrm{ZnS})$ embedded in electrospun PVA nanofibers (40-200 nm of diameter) showed improved acoustic sensitivity of $2 \mathrm{~V} / \mathrm{Pa}$ leading to harvesting energy from random acoustic vibrations. The aluminium foil from the collector during electrospinning was used as bottom electrode and as a top electrode a conductive adhesive carbon tape. A maximum power density of $1.7 \mathrm{nW} / \mathrm{mm}^{3}$ was obtained at $40 \mathrm{M} \Omega$ of resistance. In case of harvester energy from sound vibration, when a sound pressure of $100 \mathrm{~dB}$ was applied and output voltage of $4 \mathrm{~V}$ was measured [165].

Another polymeric matrix (PLLA) was used to produce electrospun nanofibers $(100 \mathrm{~nm}$ to $2 \mu \mathrm{m}$ of diameter) for an energy harvesting device on PI substrate with gold comb electrode. This device showed an open-circuit voltage of $250 \mathrm{mV}$ and short-circuit current of $96 \mathrm{nA}$ for a displacement of $1 \mathrm{~mm}$. To show the applicability on flexible energy harvesting systems, a voltage of $0.55 \mathrm{~V}$ and current of $230 \mathrm{nA}$ was observed for a strain deformation of $28.9^{\circ}$. After 2800 cycles, the system show stability on the electrical signals generated and its was applied to a human joint bending and a power generation of $9.5 \mathrm{nW}$ was observed [166]. Aligned $\mathrm{BaTiO}_{3}$ nanofibers with diameter $\approx 100-200 \mathrm{~nm}$ was electrospun and transferred to a plastic substrate coated with an interdigital electrode and embedded in PDMS. An output voltage of $\approx 0.45 \mathrm{~V}$ was generated under a load resistance of $1 \mathrm{M} \Omega$ and a frequency of $45 \mathrm{~Hz}$, corresponding to an output power of $60 \mathrm{nW}$. During the measurements, a power output of $6 \mathrm{nW}$ was observed [167]. An energy harvesting system based on electrospun fibers of $\mathrm{Bi}_{0.5} \mathrm{Na}_{0.5} \mathrm{TiO}_{3}-\mathrm{Bi}_{0.5} \mathrm{~K}_{0.5} \mathrm{TiO}_{3}$ (BNT-BKT) was applied for harvest energy from human finger movement. The nanofibers $(150 \mathrm{~nm}$ of 
diameter) were sandwiched between the bottom electrode of an ITO-coated PET film with $100 \mu \mathrm{m}$ thick and a $25 \mu \mathrm{m}$ PDMS layer, as shown in Figure 19A. The top and bottom electrode was the same. The output voltage, current and power obtained at a $60 \mathrm{M} \Omega$ load resistance knocked by a finger was $3.5 \mathrm{~V}, 280 \mathrm{nA}$ and $37.2 \mathrm{nW}$, respectively as shown in Figure 19B. The device was attached to a human finger and a voltage and current output of $0.49 \mathrm{~V}$ and $13.5 \mathrm{nA}$ was observed, and a good mechanical stability after 100 cycles was observed [168].

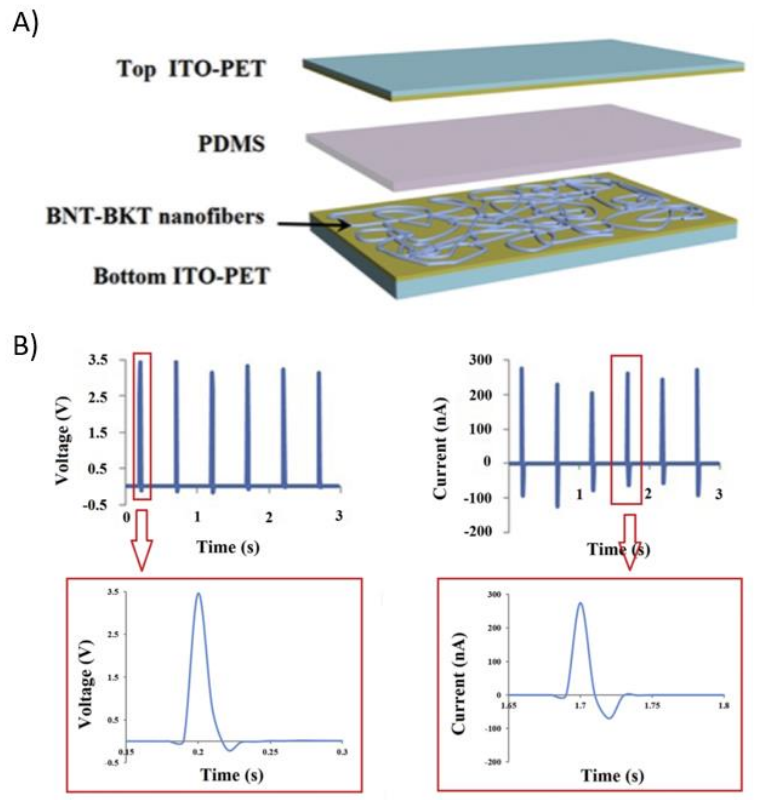

Figure 19- A) Illustration of the BNT-BKT structure; B) the open-circuit voltage (left) and short-circuit current (right) output under repeated finger-touch motion. Adapted from [168].

An energy harvesting system based on lead zirconate titanate (PZT) nanofibers (60 nm of diameter and $500 \mu \mathrm{m}$ of length) were deposited on interdigitated electrodes of platinum fine wire (diameter $50 \mu \mathrm{m}$ ) arrays in a silicon substrate. To prevent damage and to increase the life time of the nanogenerator it was embedded in a PDMS matrix. The device at a load resistance of $6 \mathrm{M} \Omega$ and frequency of $40 \mathrm{~Hz}$ generated an output voltage and power of $1.63 \mathrm{~V}$ and $0.03 \mu \mathrm{W}$, respectively [169].

A different approach was introduced by Cui, Wu [170] based on electrospun PZT nanowires on a PDMS-coated magnetite $\left(\mathrm{Fe}_{3} \mathrm{O}_{4}\right)$ substrate embedded on PDMS with top and bottom silver electrodes. Two types of noncontact magnetic force driven nanogenerators was developed using the piezoelectric potential drop along the radial 
direction and the other along the axial direction of the nanowire to generate electricity without contacting with the mechanical movement source. The device generated an output voltage of $3.2 \mathrm{~V}$, output current of $50 \mathrm{nA}$ and a maximum power density of 70 $\mu \mathrm{W} / \mathrm{cm}^{3}$. The applicability of this system to power an LCD screen was demonstrated and the noncontact magnetic driven nanogenerator open the possibility of applying the nanogenerators for magnetic sensing. Aligned PZT nanowires (diameter $370 \mathrm{~nm}$ ) electrospun on a PET substrate with top and bottom silver electrodes generated a $6 \mathrm{~V}$ open-circuit voltage and $45 \mathrm{nA}$ of short-circuit current with an output power of $0.12 \mu \mathrm{W}$ at a $100 \mathrm{M} \Omega$ load resistance. The output power density of $200 \mu \mathrm{W} / \mathrm{cm}^{3}$ was obtained. The piezoelectric layer was removed from the substrate and then measured an output voltage of $0.24 \mathrm{~V}$ and $2.5 \mathrm{nA}$ of current [171]. Other approach using aligned PZT nanowires embedded in PDMS were rotated to create vertically aligned nanowires. For an external load of $100 \mathrm{M} \Omega$, an output voltage and current of $198 \mathrm{~V}$ and $17.8 \mu \mathrm{A}$ was observed. For larger impact applied, a voltage of $209 \mathrm{~V}$ and current of $53 \mu \mathrm{A}$ was observed, corresponding to a current density of $23.5 \mu \mathrm{A} / \mathrm{cm}^{2}$ [172]. Mn-doped $\left(\mathrm{Na}_{0.5} \mathrm{~K}_{0.5}\right) \mathrm{NbO}_{3}$ (NKN) nanofibers electrospun on PES substrate and embedded in PDMS and contacted using interdigitated platinum electrodes was produced for an energy harvesting system. An open-circuit voltage and short-circuit current of $0.3 \mathrm{~V}$ and $50 \mathrm{nA}$ was measured, respectively [173]. In Table 3 it was summarized some energy harvesting system based on electrospun piezoelectric polymers and polymer-composites fibres.

Table 3-Summary of electrospun piezoelectric energy harvesting systems.

\begin{tabular}{|c|c|c|c|}
\hline Piezoelectric material & Output performance & $\begin{array}{l}\text { Measurements } \\
\text { characteristics }\end{array}$ & Ref. \\
\hline PVDF & $5 \mathrm{~V} / 400 \mathrm{nA} / 200 \mathrm{nW}$ & Load resistance $2 \mathrm{M} \Omega$ & [146] \\
\hline PVDF & $\begin{array}{c}0.52 \mathrm{~V} / 18.76 \\
\mathrm{nA} / 5.54 \mu \mathrm{W} / \mathrm{cm}^{3} \\
\end{array}$ & $\begin{array}{l}\text { Periodic pressure of } \\
0.02 \mathrm{MPa} \text { at } 1.85 \mathrm{~Hz}\end{array}$ & [147] \\
\hline PVDF & $1.6 \mathrm{~V}$ & Frequency of $2 \mathrm{~Hz}$ & [148] \\
\hline PVDF & $76 \mathrm{mV} / 39 \mathrm{nA}$ & Strain of $0.05 \%$ at $7 \mathrm{~Hz}$ & [149] \\
\hline PVDF-TrFE & $0.4 \mathrm{~V}$ & $\begin{array}{c}\text { Cantilever pressure } 8 \mathrm{mN} \\
\text { at } 3 \mathrm{~Hz}\end{array}$ & [150] \\
\hline PVDF-TrFE & $\begin{array}{c}14.5 \mathrm{~V} / 8.5 \mu \mathrm{A} / 306.5 \\
\mu \mathrm{W} / \mathrm{cm}^{3}\end{array}$ & $\begin{array}{l}\text { Sound pressure } 115 \mathrm{~dB} \text { at } \\
210 \mathrm{~Hz}\end{array}$ & [151] \\
\hline PVDF-TrFE & $\begin{array}{c}57.1 \mathrm{~V} / 2.95 \mu \mathrm{A} / 0.85 \\
\mu \mathrm{W}\end{array}$ & Load resistance $600 \mathrm{M} \Omega$ & {$[152]$} \\
\hline PVDF-TrFE & $0.02 \mu \mathrm{W}-25 \mu \mathrm{W}$ & $\begin{array}{c}\text { Load resistance } 1 \mathrm{M} \Omega \text { and } \\
\text { displacement of } 7 \mathrm{~mm}\end{array}$ & {$[153]$} \\
\hline $\mathrm{PVDF} / \mathrm{Au}$ & $4.1 \mathrm{~V} / 295 \mathrm{nA}$ & Strain of $0.5 \%$ at $5 \mathrm{~Hz}$ & [154] \\
\hline
\end{tabular}




\begin{tabular}{|c|c|c|c|}
\hline & $1.8 \mathrm{~V} / 140 \mathrm{nA}$ & & \\
\hline PVDF/MWCNTs & $6 \mathrm{~V} / 81.8 \mathrm{nW}$ & & [155] \\
\hline $\mathrm{PVDF} / \mathrm{BaTiO}_{3}$ & $0.48 \mathrm{~V}$ & $\begin{array}{c}\text { Displacement of } 6 \mathrm{~mm} \text { at } \\
0.007 \mathrm{~Hz}\end{array}$ & {$[156]$} \\
\hline PVDF-TrFE/BaTiO 3 & $25 \mathrm{~V}$ & $\begin{array}{c}\text { Walking frequency of } 0.6 \\
\mathrm{~Hz}\end{array}$ & [157] \\
\hline PVDF-TrFE/NKN & $0.98 \mathrm{~V} / 78 \mathrm{nA}$ & - & [158] \\
\hline PVDF-TrFE/PZN-PZT & $3.4 \mathrm{~V} / 240 \mathrm{nA}$ & - & [159] \\
\hline PVDF/graphene & $\begin{array}{c}3.8 \mathrm{~V}-7.9 \mathrm{~V} / 2 \mu \mathrm{A}- \\
4.5 \mu \mathrm{A}\end{array}$ & $\begin{array}{c}\text { Pressure of } 0.2 \mathrm{MPa} \text { at1 } \\
\mathrm{Hz}\end{array}$ & {$[160]$} \\
\hline${\mathrm{PVDF} / \mathrm{BaTiO}_{3} / \text { graphene }}$ & $11 \mathrm{~V} / 4.1 \mu \mathrm{W}$ & $\begin{array}{l}\text { Load frequency of } 2 \mathrm{~Hz} \\
\text { and strain of } 4 \mathrm{~mm}\end{array}$ & [161] \\
\hline $\mathrm{PVDF} / \mathrm{Pt}$ & $\begin{array}{c}30 \mathrm{~V} / 6 \mathrm{~mA} / \mathrm{cm}^{2} / 22 \\
\mu \mathrm{W} / \mathrm{cm}^{2}\end{array}$ & Load resistance of $1 \mathrm{M} \Omega$. & [162] \\
\hline PVDF-HFP/Ag & $3 \mathrm{~V} / 0.9 \mu \mathrm{A} / \mathrm{cm}^{2}$ & $\begin{array}{c}\text { Periodic pressure of } 15 \\
\mathrm{kPa} \text { at } 2 \mathrm{~Hz}\end{array}$ & {$[163]$} \\
\hline $\begin{array}{l}\text { PVDF-HFP /graphene/ } \\
\mathrm{Eu}^{3+}\end{array}$ & $\begin{array}{c}9 \mathrm{~V} / 5.8 \mu \mathrm{W} \\
4.5 \mathrm{~V} / 2.4 \mu \mathrm{W}\end{array}$ & $\begin{array}{c}\text { Pressure of } 5.6 \mathrm{kPa} \\
\text { Wind velocity of } 8.5 \mathrm{~m} / \mathrm{s} \\
\text { and incident angle of } 45^{\circ}\end{array}$ & [164] \\
\hline PVA/ZnS & $\begin{array}{c}1.7 \mathrm{nW} / \mathrm{mm}^{-3} \\
4 \mathrm{~V}\end{array}$ & $\begin{array}{c}\text { Load resistance } 40 \mathrm{M} \Omega \\
\text { Sound pressure of } 100 \mathrm{~dB}\end{array}$ & [165] \\
\hline PLLA & $\begin{array}{c}250 \mathrm{mV} / 96 \mathrm{nA} \\
0.55 \mathrm{~V} / 230 \mathrm{nA} / 9.5 \\
\mathrm{nW} \\
\end{array}$ & $\begin{array}{l}\text { Displacement of } 1 \mathrm{~mm} \\
\text { Deformation of } 28.9^{\circ}\end{array}$ & [166] \\
\hline $\mathrm{BaTiO}_{3}$ & $0.45 \mathrm{~V} / 60 \mathrm{nW}$ & $\begin{array}{c}\text { Load resistance of } 1 \mathrm{M} \Omega \\
\text { at } 45 \mathrm{~Hz}\end{array}$ & [167] \\
\hline BNT-BKT & $\begin{array}{c}3.5 \mathrm{~V} / 280 \mathrm{nA} / 37.2 \\
\mathrm{nW}\end{array}$ & Load resistance $60 \mathrm{M} \Omega$ & [168] \\
\hline PZT & $1.63 \mathrm{~V} / 0.03 \mu \mathrm{W}$ & $\begin{array}{c}\text { Load resistance of } 6 \mathrm{M} \Omega \\
\text { at } 40 \mathrm{~Hz}\end{array}$ & [169] \\
\hline PZT & $\begin{array}{c}3.2 \mathrm{~V} / 50 \mathrm{nA} / 70 \\
\mu \mathrm{W} / \mathrm{cm}^{3}\end{array}$ & - & {$[170]$} \\
\hline $\mathrm{PZT}$ & $6 \mathrm{~V} / 45 \mathrm{nA} / 0.12 \mu \mathrm{W}$ & Load resistance $100 \mathrm{M} \Omega$ & [171] \\
\hline PZT & $\begin{array}{c}198 \mathrm{~V} / 17.8 \mu \mathrm{A} \\
209 \mathrm{~V} / 53 \mu \mathrm{A}\end{array}$ & $\begin{array}{l}\text { Load resistance of } 100 \\
\mathrm{M} \Omega\end{array}$ & {$[172]$} \\
\hline NKN & $0.3 \mathrm{~V} / 50 \mathrm{nA}$ & - & {$[173]$} \\
\hline
\end{tabular}

\section{Final remarks}

Electrospun piezoelectric nanofibers have attracted increasing attention due to their specific microstructure, excellent mechanical properties and, in some cases, biocompatibility. 
The main concepts, materials and device applications related to electrospun piezoelectric materials have been presented, mainly focussing on energy harvesting systems based on electrospun piezoelectric polymers and polymer-composites.

Piezoelectric electrospun energy harvesting materials convert mechanical vibrations from the environment into electrical energy that can be used to power micro/nanodevices. Among the different materials, the piezoelectric polymer PVDF has been particularly studied due to its high flexibility and long-term physical/chemical stability. Further, electrospun ceramic materials such as $\mathrm{BaTiO}_{3}$ and PZT; among others, have been also developed.

Despite the findings reported on the developments of piezoelectric electrospun materials for energy harvesting, there are relevant issues that need to be addressed. Those issues are mainly concern with improving materials performance for meeting a large spectra um applications demands, but also time stability and simplicity in device integration, to meet manufacturing demands. In this sense, polymer-composite electrospun materials can play a relevant role in the near future allowing to combine the low-cost, higher versatility, stability and flexibility of the polymers with the higher response of the inorganic piezoelectric materials.

Finally, due to the increasingly important environmental concerns more environmentalfriendly solvents and recyclable materials must be used in this field.

Piezoelectric electropun materials offer relevant scientific challenges and present large technological interest, playing an increasing and needed role in key areas such as sensing, energy harvesting, and in the biomedical field, among others.

\section{Acknowledgments}

This work was supported by the Portuguese Foundation for Science and Technology (FCT) in the framework of the Strategic Funding UID/FIS/04650/2013 and projects NORTE-01-0145-FEDER-028237， POCI-01-0145-FEDER-028159， PTDC/EEISII/5582/2014 and PTDC/CTM-ENE/5387/2014. TM, ACL, PC and PLM thanks to FCT by financial support for the SFRH/BD/140242/2018, SFRH/BD/132624/2017, SFRH/BPD/110914/2015, SFRH/BPD/96227/2013 and SFRH/BD/98219/2013 grants, respectively. Financial support from the Spanish Ministry of Economy and Competitiveness (MINECO) through the project MAT2016-76039-C4-3-R (AEI/FEDER, UE) (including the FEDER financial support) and from the Basque 
Government Industry and Education Departments under the ELKARTEK, HAZITEK and PIBA (PIBA-2018-06) programs, respectively, are acknowledged. 


\section{References}

1. Murphy, E.B. and F. Wudl, The world of smart healable materials. Progress in Polymer Science (Oxford), 2010. 35(1-2): p. 223-251.

2. Ribeiro, C., et al., Electroactive poly(vinylidene fluoride)-based structures for advanced applications. Nature Protocols, 2018. 13(4): p. 681-704.

3. Hinchet, R., W. Seung, and S.W. Kim, Recent Progress on Flexible Triboelectric Nanogenerators for SelfPowered Electronics. ChemSusChem, 2015. 8(14): p. 2327-2344.

4. Jain, A., et al., Dielectric and piezoelectric properties of PVDF/PZT composites: A review. Polymer Engineering and Science, 2015. 55(7): p. 1589-1616.

5. Silva, M., et al., Optimization of the magnetoelectric response of poly(vinylidene fluoride)/epoxy/vitrovac laminates. ACS Applied Materials and Interfaces, 2013. 5(21): p. 10912-10919.

6. $\quad$ Phan, H., et al., The Piezoresistive Effect of SiC for MEMS Sensors at High Temperatures: A Review. Journal of Microelectromechanical Systems, 2015.

7. Song, I.S., et al., Sensitivity enhancement of a UV photo-sensor based on a fiber Bragg grating coated by a photomechanical functional polymer. Sensors and Actuators, A: Physical, 2015. 232: p. 223-228.

8. Romero Gómez, J., et al., Magnetocaloric effect: A review of the thermodynamic cycles in magnetic refrigeration. Renewable and Sustainable Energy Reviews, 2013. 17: p. 7482.

9. Khan, A., et al., Piezoelectric thin films: An integrated review of transducers and energy harvesting. Smart Materials and Structures, 2016. 25(5).

10. Jung, J., et al., Review of piezoelectric micromachined ultrasonic transducers and their applications. Journal of Micromechanics and Microengineering, 2017. 27(11).

11. Tiersten, H.F., Linear Piezoelectric Plate Vibrations : Elements of the Linear Theory of Piezoelectricity and the Vibrations of Piezoelectric Plates. 1995: Springer US.

12. Narita, F. and M. Fox, A Review on Piezoelectric, Magnetostrictive, and Magnetoelectric Materials and Device Technologies for Energy Harvesting Applications. Advanced Engineering Materials, 2018. 20(5).

13. Martins, P. and S. Lanceros-Méndez, Polymer-based magnetoelectric materials. Advanced Functional Materials, 2013. 23(27): p. 3371-3385.

14. Martins, P., A.C. Lopes, and S. Lanceros-Mendez, Electroactive phases of poly(vinylidene fluoride): Determination, processing and applications. Progress in Polymer Science, 2014. 39(4): p. 683-706.

15. Tiwari, S., et al., Enhanced piezoelectric response in nanoclay induced electrospun PVDF nanofibers for energy harvesting. Energy, 2019. 171: p. 485-492.

16. Erturk, A. and D.J. Inman, Piezoelectric Energy Harvesting. Piezoelectric Energy Harvesting. 2011.

17. Pradeep Fulay, J.-K.L., Electronic, Magnetic, and Optical Materials. 2010, Taylor \& Francis Inc: Bosa Roca, United States.

18. Nunes-Pereira, J., P. Costa, and S. Lanceros-Mendez, 3.9 Piezoelectric Energy Production, in Comprehensive Energy Systems, I. Dincer, Editor. 2018, Elsevier: Oxford. p. 380-415.

19. Jiří, E., Experiments to demonstrate piezoelectric and pyroelectric effects. Physics Education, 2013. 48(4): p. 438.

20. Zhang, S. and F. Li, High performance ferroelectric relaxor-PbTiO3 single crystals: Status and perspective. Journal of Applied Physics, 2012. 111(3): p. 031301.

21. Khaled, S.R., D. Sameoto, and S. Evoy, A review of piezoelectric polymers as functional materials for electromechanical transducers. Smart Materials and Structures, 2014. 23(3): p. 033001.

22. Harb, A., Energy harvesting: State-of-the-art. Renewable Energy, 2011. 36(10): p. 26412654. 
23. Vullers, R.J.M., et al., Micropower energy harvesting. Solid-State Electronics, 2009. 53(7): p. 684-693.

24. Proto, A., et al., Nanogenerators for Human Body Energy Harvesting. Trends in Biotechnology, 2017. 35(7): p. 610-624.

25. Wang, H., A. Jasim, and X. Chen, Energy harvesting technologies in roadway and bridge for different applications - A comprehensive review. Applied Energy, 2018. 212: p. 10831094.

26. Shanmugam, V., S. Selvakumar, and C.S. Yeh, Near-infrared light-responsive nanomaterials in cancer therapeutics. Chem. Soc. Rev., 2014. 43(17): p. 6254-87.

27. Shi, H., et al., Preparation of functionalized graphene/SEBS-g-MAH nanocomposites and improvement of its electrical, mechanical properties. Materials Letters, 2014. 133: p. 200-203.

28. Sridhar, R. and S. Ramakrishna, Electrosprayed nanoparticles for drug delivery and pharmaceutical applications. Biomaterials, 2013. 3(3).

29. Dewangan, K., et al., Synthesis and characterization of self-assembled nanofiber-bundles of V2O5: their electrochemical and field emission properties. Nanoscale, 2012. 4(2): p. 645-651.

30. Lakshmi, B.B., C.J. Patrissi, and C.R. Martin, Sol-Gel Template Synthesis of Semiconductor Oxide Micro- and Nanostructures. Chemistry of Materials, 1997. 9(11): p. 2544-2550.

31. Badrossamay, M.R., et al., Nanofiber assembly by rotary jet-spinning. Nano Letters, 2010. 9(10): p. 2257-61.

32. Beachley, V. and X. Wen, Polymer nanofibrous structures: Fabrication, biofunctionalization, and cell interactions. Progress in Polymer Science, 2010. 1(35): p. 868-892.

33. Dersch, R., et al., Electrospinning of Nanofibres: Towards New Techniques, Functions, and Applications. Australian Journal of Chemistry, 2007. 60(10): p. 719-719.

34. Yoo, H.S., T.G. Kim, and T.G. Park, Surface-functionalized electrospun nanofibers for tissue engineering and drug delivery. Advanced Drug Delivery Reviews, 2009. 61(12): p. 1033-42.

35. Liu, X. and P.X. Ma, Phase separation, pore structure, and properties of nanofibrous gelatin scaffolds. Biomaterials, 2009. 30(25): p. 4094-103.

36. Ellison, C.J., et al., Melt blown nanofibers: Fiber diameter distributions and onset of fiber breakup. Chemical Engineering and Materials Science, 2007. 48(11): p. 3306-3316.

37. Leach, M.K., et al., Electrospinning Fundamentals: Optimizing Solution and Apparatus Parameters. Journal of Visualized Experiments, 2011. 47.

38. KoŠŤÁKovÁa, E., et al. Electrospinning and Electrospraying of polymer solutions with spherical fullrenes.

39. Bhushania, J.A. and C. Anandharamakrishnana, Electrospinning and electrospraying techniques: Potential food based applications. Trends in Food Science \& Technology, 2014. 38: p. 21-33.

40. Kessick, R., J. Fenn, and G. Tepper, The use of AC potentials in electrospraying and electrospinning processes. Polymer, 2004. 45(9): p. 2981-2989.

41. Reneker, D.H. and A.L. Yarin, Electrospinning jets and polymer nanofibers. Polymer, 2008. 49(10): p. 2387-2425.

42. Dersch, R., et al., Nanoprocessing of polymers: applications in medicine, sensors, catalysis, photonics. Polym. Adv. Technol., 2005. 16: p. 276-282.

43. Tapia-Hernandez, J.A., et al., Micro- and Nanoparticles by Electrospray: Advances and Applications in Foods. Journal of Agricultural and Food Chmeistry, 2015. 63(19): p. 46994707.

44. Vonnegut, B. and R.L. Neubauer, Production of monodisperse liquid particles by electrical atomization. J. Colloid Sci., 1952. 7: p. 616-622. 
45. Pillay, V., et al., A Review of the Effect of Processing Variables on the Fabrication of Electrospun Nanofibers for Drug Delivery Applications. Journal of Nanomaterials, 2013: p. 22-22.

46. Chen, J.-Y., et al., Electrospun nanofibers with dual plasmonic-enhanced luminescent solar concentrator effects for high-performance organic photovoltaic cells. Journal of Materials Chemistry A, 2015(29): p. 15039-15048.

47. Thavasi, V., G. Singh, and S. Ramakrishna, Electrospun nanofibers in energy and environmental applications. Energy and Environmental Science, 2008. 1(2): p. 205-221.

48. Sankaran, K.K., et al., Development and evaluation of axially aligned nanofibres for blood vessel tissue engineering. Journal of Tissue Engineering and Regenerative Medicine, 2014. 8(8): p. 640-651.

49. Sorayani Bafqi, M.S., R. Bagherzadeh, and M. Latifi, Nanofiber alignment tuning: An engineering design tool in fabricating wearable power harvesting devices. Journal of Industrial Textiles, 2017. 47(4): p. 535-550.

50. Kim, K.W., et al., The effect of molecular weight and the linear velocity of drum surface on the properties of electrospun poly(ethylene terephthalate) nonwovens. Fibers and Polymers, 2004. 5(2): p. 122-127.

51. Dersch, R., et al., Electrospun nanofibers: internal structure and intrinsic orientation. Journal of Polymer Science, Part A: Polymer Chemistry, 2003. 41(4): p. 545-553.

52. Li, D., Y. Wang, and Y. Xia, Electrospinning of polymeric and ceramic nanofibers as uniaxially aligned arrays. Nano Letters, 2003. 3(8): p. 1167-1171.

53. Teo, W.E., et al., A dynamic liquid support system for continuous electrospun yarn fabrication. Polymer, 2007. 48(12): p. 3400-3405.

54. Huanga, Z.-M., et al., A review on polymer nanofibers by electrospinning and their applications in nanocomposites. Composites Science and Technology, 2003. 63: p. 22232253.

55. Dagdeviren, C., et al., Recent progress in flexible and stretchable piezoelectric devices for mechanical energy harvesting, sensing and actuation. Extreme Mechanics Letters, 2016. 9: p. 269-281.

56. Bognitzki, M., et al., Nanostructured fibers via electrospinning. Advanced Materials, 2001. 13: p. 70-72.

57. MacDiarmid, A.G., et al., Electrostatically-generated nanofibers of electronic polymers. Synthetic Metals, 2001. 119: p. 27-30.

58. Buchko, C.J., et al., Processing and microstructural characterization of porous biocompatible protein polymer thin films. Polymer, 1999. 40: p. 7397-7407.

59. Koombhongse, S., W.X. Liu, and D.H. Reneker, Flat polymer ribbons and other shapes by electrospinning. J. Polym. Sci. B, Polym. Phys., 2001. 39: p. 598-606.

60. Ribeiro, C., et al., Influence of processing conditions on polymorphism and nanofiber morphology of electroactive poly(vinylidene fluoride) electrospun membranes. Soft Materials, 2010. 8(3): p. 274-287.

61. Liu, H.Q. and Y.L. Hsieh, Ultrafine fibrous cellulose membranes from electrospinning of cellulose acetate. J. Polym. Sci. B, Polym. Phys., 2002. 40: p. 2119-2129.

62. Bergshoef, M.M. and G.J. Vancso, Transparent nanocomposites with ultrathin, electrospun Nylon-4,6 fiber reinforcement. Advanced Materials, 1999. 11(16): p. 13621365.

63. Kenawy, E.R., et al., Electrospinning of poly (ethylene-covinyl alcohol) fibers. Biomaterials, 2003. 24(907-913).

64. Kenawy, E.R. and Y.R. Abdel-Fattah, Antimicrobial properties of modified and electrospn poly (vunl phenol). Macromolecular bioscience, 2002. 2: p. 261-266.

65. Wang, X.Y., et al., Highly sensitive optical sensors using electrospun polymeric nanofibrous membranes. Mat Res Soc Symp Pro, 2002. 708: p. 397-402. 
66. Torres, B., Ultrafine fibers of polystyrene dissolved in tetrahydrofuran prepared using the electrospinning method. Proceeding of the National Conference On Undergraduate Research, 2001. 15(17): p. 1-5.

67. Theron, A., E. Zussman, and A.L. Yarin, Electrostatic field-assisted alignment of electrospun nanofibres. Nanotechnology, 2001. 12: p. 384-390.

68. Wua, C.M., et al. Sound absorption of electrospun polyvinylidene fluoride/carbon nanotube membranes. Copenhagen.

69. Xia, W. and Z. Zhang, PVDF-based dielectric polymers and their applications in electronic materials. IET Nanodielectrics, 2018. 1(1): p. 17-31.

70. $\mathrm{Li}$, L., et al., Studies on the transformation process of PVDF from $\alpha$ to $B$ phase by stretching. RSC Advances, 2014. 4(8): p. 3938-3943.

71. Sencadas, V., R. Gregorio Jr, and S. Lanceros-Méndez, $\alpha$ to 8 phase transformation and microestructural changes of PVDF films induced by uniaxial stretch. Journal of Macromolecular Science, Part B: Physics, 2009. 48(3): p. 514-525.

72. Gregorio Jr, R. and D.S. Borges, Effect of crystallization rate on the formation of the polymorphs of solution cast poly(vinylidene fluoride). Polymer, 2008. 49(18): p. 40094016.

73. Sharma, M., G. Madras, and S. Bose, Process induced electroactive 6-polymorph in PVDF: Effect on dielectric and ferroelectric properties. Physical Chemistry Chemical Physics, 2014. 16(28): p. 14792-14799.

74. Okada, D., et al., Colloidal crystallization and ionic liquid induced partial 8-phase transformation of poly(vinylidene fluoride) nanoparticles. Macromolecules, 2015. 48(8): p. 2570-2575.

75. Martins, P., et al., On the origin of the electroactive poly(vinylidene fluoride) 6-phase nucleation by ferrite nanoparticles via surface electrostatic interactions. CrystEngComm, 2012. 14(8): p. 2807-2811.

76. Kim, G.H., S.M. Hong, and Y. Seo, Piezoelectric properties of poly(vinylidene fluoride) and carbon nanotube blends: 6-phase development. Physical Chemistry Chemical Physics, 2009. 11(44): p. 10506-10512.

77. Miranda, D., et al., Influence of silver nanoparticles concentration on the $\alpha$-to 6 -phase transformation and the physical properties of silver nanoparticles doped poly(vinylidene fluoride) nanocomposites. Journal of Nanoscience and Nanotechnology, 2009. 9(5): p. 2910-2916.

78. Ouyang, Z.-W., Z.-M. Wu, and E.-C. Chen, Enhanced piezoelectric and mechanical properties of electroactive polyvinylidene fluoride/iron oxide composites. Materials Chemistry and Physics, 2015. 1: p. 149-150.

79. Nandi, A.K. and L. Mandelkern, The influence of chain structure on the equilibrium melting temperature of poly(vinylidene fluoride). Journal of Polymer Science, Part B: Polymer Physics, 1991.

80. Wang, Y.R., et al., A flexible piezoelectric force sensor based on PVDF fabrics. Smart Mater. Struc., 2011. 20.

81. Liu, Z.H., et al., Direct-write PVDF nonwoven fiber fabric energy harvesters via the hollow cylindrical near-field electrospinning process. Smart Materials and Structures, 2014. 23.

82. Yu, L., et al. Piezoelectric performance of aligned PVDF nanofibers fabricated by electrospinning and mechanical spinning. Beijing.

83. Yun, J.S., et al., The Fabrication and Characterization of Piezoelectric PZT/PVDF Electrospun Nanofiber Composites. Nanomaterials and Nanotechnology, 2016. 6: p. 2020.

84. Shashank, P., et al., Piezoelectric and Magnetoelectric Thick Films for Fabricating Power Sources in Wireless Sensor Nodes. Sensors, 2009. 9: p. 6362-6384.

85. Li, D. and Y. Xia, Electrospinning of nanofibers: Reinventing the wheel? Advanced Materials, 2004. 15. 
86. Kumar, P.S., et al., Hierarchical electrospun nanofibers for energy harvesting, production and environmental remediation. Energy and Environmental Science, 2014. 7(10): p. 3192-3222.

87. Wan, T., S. Ramakrishna, and L. Yong, Recent progress in electrospinning TiO2 nanostructured photoanode of dye sensitized solar cells. Journal of Applied Polymer Science, 2018. 135(1).

88. Luan, J. and Y. Li, Photocatalytic Water Splitting for Hydrogen Production with $\mathrm{Gd}_{2} \mathrm{MSbO}_{7}$ $(M=F e, I n, Y)$ Photocatalysts under Visible Light Irradiation. Materials (Basel, Switzerland), 2014. 8(1): p. 16-30.

89. Ico, G., et al., Size-dependent piezoelectric and mechanical properties of electrospun $P($ VDF-TrFE) nanofibers for enhanced energy harvesting. Journal of Materials Chemistry A, 2016. 4(6): p. 2293-2304.

90. Zhu, J., L. Jia, and R. Huang, Electrospinning poly(I-lactic acid) piezoelectric ordered porous nanofibers for strain sensing and energy harvesting. Journal of Materials Science: Materials in Electronics, 2017. 28(16): p. 12080-12085.

91. Liu, K., et al., Piezoelectric energy harvesting and charging performance of $\mathrm{Pb}(\mathrm{Zn}<$ inf $>1 / 3</$ inf $>\mathrm{Nb}<$ inf $>2 / 3</$ inf $>)$ O $<$ inf $>3</$ inf $>-$

$\mathrm{Pb}(\mathrm{Zr}<\mathrm{inf}>0.5</$ inf $>\operatorname{Ti}<$ inf $>0.5</$ inf $>)$ O $<$ inf $>3</$ inf $>$ nanoparticle-embedded $P($ VDF-TrFE) nanofiber composite sheets. Composites Science and Technology, 2018. 168: p. 296-302.

92. Sahatiya, P., S. Kannan, and S. Badhulika, Few layer MoS $<$ inf $>2</$ inf $>$ and in situ poled PVDF nanofibers on low cost paper substrate as high performance piezo-triboelectric hybrid nanogenerator: Energy harvesting from handwriting and human touch. Applied Materials Today, 2018. 13: p. 91-99.

93. Dineva, P.S., et al., Piezoelectric Materials. 2014, Springer International Publishing: Switzerland. p. 119-119.

94. Gerhard-Multhaupt, R., Less can be more. Holes in polymers lead to a new paradigm of piezoelectric materials for electret transducers. IEEE Transactions on Dielectrics and Electrical Insulation, 2002. 9(5): p. 850-859.

95. Ounaies, Z., J.A. Young, and J.S. Harrison, An Overview of the Piezoelectric Phenomenon in Amorphous Polymers, in Field Responsive Polymers. 1999, American Chemical Society. p. 88-103.

96. Mark, H.F., Encyclopedia of Polymer Science and Technology, Concise. 2013: Wiley.

97. Naohiro, M. and O. Hiroshi, Piezoelectric Polymers and Their Applications. Japanese Journal of Applied Physics, 1983. 22(S3): p. 3.

98. Nakamura, K., Ultrasonic Transducers: Materials and Design for Sensors, Actuators and Medical Applications. 2012: Elsevier Science.

99. Mendes, S.F., et al., Effect of filler size and concentration on the structure and properties of poly(vinylidene fluoride)/BaTiO3 nanocomposites. Journal of Materials Science, 2012. 47(3): p. 1378-1388.

100. Patro, T.U., et al., Studies on poly(vinylidene fluoride)-clay nanocomposites: Effect of different clay modifiers. Polymer, 2008. 49(16): p. 3486-3499.

101. Dias, J.C., et al., Electromechanical actuators based on poly(vinylidene fluoride) with [N1 11 2(OH)][NTf2] and [C2mim] [C2SO4]. Journal of Materials Science, 2016. 51(20): p. $9490-9503$.

102. Martins, P., et al., Optimizing piezoelectric and magnetoelectric responses on CoFe204/P (VDF-TrFE) nanocomposites. Journal of Physics D: Applied Physics, 2011. 44(49): $p$. 495303.

103. Xu, Y., Ferroelectric Materials and Their Applications. 2013: Elsevier Science.

104. Sousa, R.E., et al., Microstructural variations of poly(vinylidene fluoride cohexafluoropropylene) and their influence on the thermal, dielectric and piezoelectric properties. Polymer Testing, 2014. 40: p. 245-255. 
105. Sousa, R.E., et al., Tailoring poly(vinylidene fluoride-co-chlorotrifluoroethylene) microstructure and physicochemical properties by exploring its binary phase diagram with dimethylformamide. Journal of Polymer Science, Part B: Polymer Physics, 2015. 53(11): p. 761-773.

106. Cardoso, V.F., et al., Fluorinated polymers as smart materials for advanced biomedical applications. Polymers, 2018. 10(2).

107. Dong, R., et al., First-principles simulations of PVDF copolymers with high dielectric energy density: PVDF-HFP and PVDF-BTFE. Physical Review B, 2016. 94(1).

108. Fukada, E. Recent developments of piezoelectric polymers - polyurea, odd-nylon, vinylidenecyanide copolymer, and polylactic acid. in 2005 12th International Symposium on Electrets. 2005.

109. Ribeiro, C., et al., Piezoelectric polymers as biomaterials for tissue engineering applications. Colloids and Surfaces B: Biointerfaces, 2015. 136: p. 46-55.

110. Li, Y., et al., Dielectric and piezoelecrtic properties of lead-free (Na0.5Bi0.5)TiO3$\mathrm{NaNbO} 3$ ceramics. Materials Science and Engineering: B, 2004. 112(1): p. 5-9.

111. Petzelt, J., Dielectric grain-size effect in high-permittivity ceramics. Ferroelectrics, 2010. 400(1): p. 117-134.

112. Hu, S., et al., Multifunctional piezoelectric elastomer composites for smart biomedical or wearable electronics. Composites Part B: Engineering, 2019. 160: p. 595-604.

113. Saha-Dasgupta, T., Ferroic properties in bi-component perovskites: artificial superlattices and naturally forming compounds. Journal of Physics: Condensed Matter, 2014. 26(19): p. 193201.

114. Kang, M.-G., et al., Recent Progress on PZT Based Piezoelectric Energy Harvesting Technologies. Actuators, 2016. 5(1): p. 5.

115. Cheng, L.-Q. and J.-F. Li, A review on one dimensional perovskite nanocrystals for piezoelectric applications. Journal of Materiomics, 2016. 2(1): p. 25-36.

116. Waser, R., Ceramic Materials for Electronics; Processing, Properties, and Applications, 2. ed. R. C. Buchanan (Ed.), Marcel Dekker Inc., New York 1991; XII, 532 pp., hardcover, \$ 166.75, ISBN 0-8247-8194-5. Advanced Materials, 1992. 4(4): p. 311-311.

117. Kenji, U., Glory of piezoelectric perovskites. Science and Technology of Advanced Materials, 2015. 16(4): p. 046001.

118. Yao, Z., et al., Morphotropic Phase Boundary of (BiO.9La0.1)ScO3-PbTiO3 Piezoelectric Ceramics for High-Temperature Application. Ferroelectrics, 2010. 409(1): p. 21-26.

119. Pardo, L. and J. Ricote, Multifunctional Polycrystalline Ferroelectric Materials: Processing and Properties. 2011: Springer Netherlands.

120. Reichmann, K., A. Feteira, and M. Li, Bismuth Sodium Titanate based materials for piezoelectric actuators. Materials, 2015. 8(12): p. 8467-8495.

121. Dunmin, L., et al., Lead-free piezoelectric ceramic ( $\mathrm{K} 0.5 \mathrm{Na} 0.5$ ) NbO 3 with MnO 2 and K 5.4 CU 1.3 Ta 10029 doping for piezoelectric transformer application. Smart Materials and Structures, 2008. 17(3): p. 035002.

122. Panda, P.K., Review: environmental friendly lead-free piezoelectric materials. Journal of Materials Science, 2009. 44(19): p. 5049-5062.

123. Pan, Z., et al., Enhanced Piezoelectric Properties of Tetragonal (Bi1/2K1/2)TiO3 LeadFree Ceramics by Substitution of Pure Bi-Based Bi(Mg2/3Nb1/3)O3. Journal of the American Ceramic Society, 2015. 98(1): p. 104-108.

124. Ye, Z.G., Handbook of Advanced Dielectric, Piezoelectric and Ferroelectric Materials: Synthesis, Properties and Applications. 2008: Elsevier Science.

125. Korir, K.K., G. Cicero, and A. Catellani, Piezoelectric properties of zinc oxide nanowires: an ab initio study. Nanotechnology, 2013. 24(47): p. 475401.

126. Wang, X., et al., Direct-Current Nanogenerator Driven by Ultrasonic Waves. Science, 2007. 316(5821): p. 102-105. 
127. Mansingh, A. and S.S. Bawa, Dielectric properties of compressed Rochelle-salt powders. physica status solidi (a), 1974. 21(2): p. 725-731.

128. Wei, C. and X. Jing, A comprehensive review on vibration energy harvesting: Modelling and realization. Renewable and Sustainable Energy Reviews, 2017. 74: p. 1-18.

129. Kong, L.B., et al., Lead zinc niobate (PZN)-barium titanate (BT) ceramics from mechanochemically synthesized powders. Materials Research Bulletin, 2002. 37(15): p. 2491-2498.

130. Thorp, J.S., et al., The dielectric properties of aluminium nitride substrates for microelectronics packaging. Journal of Materials Science, 1990. 25(12): p. 4965-4971.

131. Mortet, V., et al., Physical properties of polycrystalline aluminium nitride films deposited by magnetron sputtering. Diamond and Related Materials, 2004. 13(4): p. 1120-1124.

132. Jacob, M.V., et al. Lithium tantalate - a high permittivity dielectric material for microwave communication systems. in TENCON 2003. Conference on Convergent Technologies for Asia-Pacific Region. 2003.

133. Zhang, S.J., et al., 5 - High-performance, high-TC piezoelectric crystals, in Handbook of Advanced Dielectric, Piezoelectric and Ferroelectric Materials, Z.-G. Ye, Editor. 2008, Woodhead Publishing. p. 130-157.

134. Yue, W. and J. Yi-jian, Crystal orientation dependence of piezoelectric properties in LiNbO3 and LiTaO3. Optical Materials, 2003. 23(1): p. 403-408.

135. Han, P., J. Tian, and W. Yan, 1 - Bridgman growth and properties of PMN-PT-based single crystals, in Handbook of Advanced Dielectric, Piezoelectric and Ferroelectric Materials, Z.-G. Ye, Editor. 2008, Woodhead Publishing. p. 3-37.

136. Guo, R., et al., Comprehensive analysis of Mn:PIN-PMN-PT single crystals for Class IV flextensional transducer. Ceramics International, 2018. 44(3): p. 2864-2868.

137. Lee, H.Y., 6 - Development of high-performance piezoelectric single crystals by using solid-state single crystal growth (SSCG) method, in Handbook of Advanced Dielectric, Piezoelectric and Ferroelectric Materials, Z.-G. Ye, Editor. 2008, Woodhead Publishing. p. $158-172$.

138. Lim, L.C., 2 - Flux growth and characterization of PZN-PT and PMN-PT single crystals, in Handbook of Advanced Dielectric, Piezoelectric and Ferroelectric Materials, Z.-G. Ye, Editor. 2008, Woodhead Publishing. p. 38-72.

139. Chaudhari, V.A. and G.K. Bichile, Synthesis, Structural, and Electrical Properties of Pure PbTiO3 Ferroelectric Ceramics. Smart Materials Research, 2013. 2013: p. 9.

140. Kurosawa, M.K., 4 - Thin-film PZT-based transducers, in Ultrasonic Transducers, K. Nakamura, Editor. 2012, Woodhead Publishing. p. 117-153.

141. Yoo, J., et al., Dielectric and piezoelectric characteristics of lead-free Bi0.5(Na0.84K0.16)0.5TiO3 ceramics substituted with Sr. Materials Letters, 2004. 58(29): p. 3831-3835.

142. Kantha, P., et al., Structural and electrical properties of BZT-added BNLT ceramics. Ceramics International, 2014. 40(3): p. 4251-4256.

143. Elvin, N. and A. Erturk, Advances in Energy Harvesting Methods. 10 ed. 2013: Springer New York.

144. Lu, Q.Q., et al., Dynamic responses of SMA-epoxy composites and application for piezoelectric energy harvesting. Composite Structures, 2016. 153: p. 843-850.

145. Koh, S.J.A., et al., Dielectric Elastomer Generators: How Much Energy Can Be Converted? leee-Asme Transactions on Mechatronics, 2011. 16(1): p. 33-41.

146. Fuh, Y.K., et al., Self-Powered Active Sensor with Concentric Topography of Piezoelectric Fibers. Nanoscale Research Letters, 2017. 12: p. 8.

147. Gao, H., et al., High-performance flexible yarn for wearable piezoelectric nanogenerators. Smart Materials and Structures, 2018. 27(9): p. 11.

148. Kang, S.B., et al., Enhanced piezoresponse of highly aligned electrospun poly(vinylidene fluoride) nanofibers. Nanotechnology, 2017. 28(39): p. 11. 
149. Liu, Z.H., et al., Direct-write PVDF nonwoven fiber fabric energy harvesters via the hollow cylindrical near-field electrospinning process. Smart Materials and Structures, 2014. 23(2): p. 11.

150. Beringer, L.T., et al., An electrospun PVDF-TrFe fiber sensor platform for biological applications. Sensors and Actuators a-Physical, 2015. 222: p. 293-300.

151. Lang, C.H., et al., High-output acoustoelectric power generators from poly(vinylidenefluoride-co-trifluoroethylene) electrospun nano-nonwovens. Nano Energy, 2017. 35: p. 146-153.

152. Chen, X.X., et al., Flexible fiber-based hybrid nanogenerator for biomechanical energy harvesting and physiological monitoring. Nano Energy, 2017. 38: p. 43-50.

153. Nunes-Pereira, J., et al., Energy harvesting performance of piezoelectric electrospun polymer fibers and polymer/ceramic composites. Sensors and Actuators A-Physical, 2013. 196: p. 55-62.

154. Fuh, Y.K., et al., All-fiber transparent piezoelectric harvester with a cooperatively enhanced structure. Nanotechnology, 2016. 27(43): p. 10.

155. Yu, H., et al., Enhanced power output of an electrospun PVDF/MWCNTs-based nanogenerator by tuning its conductivity. Nanotechnology, 2013. 24(40): p. 9.

156. Lee, C., et al., Electrospun uniaxially-aligned composite nanofibers as highly-efficient piezoelectric material. Ceramics International, 2016. 42(2): p. 2734-2740.

157. Siddiqui, S., et al., A durable and stable piezoelectric nanogenerator with nanocomposite nanofibers. embedded in an elastomer under high loading for a self-powered sensor system. Nano Energy, 2016. 30: p. 434-442.

158. Kang, H.B., et al., $(\mathrm{Na}, \mathrm{K}) \mathrm{NbO3}$ nanoparticle-embedded piezoelectric nanofiber composites for flexible nanogenerators. Composites Science and Technology, 2015. 111: p. 1-8.

159. Liu, K., et al., Piezoelectric energy harvesting and charging performance of $\mathrm{Pb}(\mathrm{Zn} 1 / 3 \mathrm{Nb2} / 3) \mathrm{O} 3-\mathrm{Pb}$ (ZrO.5Ti0.5)O3 nanoparticle-embedded P(VDF-TrFE) nanofiber composite sheets. Composites Science and Technology, 2018. 168: p. 296-302.

160. Abolhasani, M.M., K. Shirvanimoghaddam, and M. Naebe, PVDF/graphene composite nanofibers with enhanced piezoelectric performance for development of robust nanogenerators. Composites Science and Technology, 2017. 138: p. 49-56.

161. Shi, K.M., et al., Synergistic effect of graphene nanosheet and BaTiO3 nanoparticles on performance enhancement of electrospun PVDF nanofiber mat for flexible piezoelectric nanogenerators. Nano Energy, 2018. 52: p. 153-162.

162. Ghosh, S.K. and D. Mandal, Synergistically enhanced piezoelectric output in highly aligned 1D polymer nanofibers integrated all-fiber nanogenerator for wearable nanotactile sensor. Nano Energy, 2018. 53: p. 245-257.

163. Mandal, D., K. Henkel, and D. Schmeisser, Improved performance of a polymer nanogenerator based on silver nanoparticles doped electrospun P(VDF-HFP) nanofibers. Physical Chemistry Chemical Physics, 2014. 16(22): p. 10403-10407.

164. Adhikary, P., A. Biswas, and D. Mandal, Improved sensitivity of wearable nanogenerators made of electrospun Eu3+ doped P(VDF-HFP)/graphene composite nanofibers for selfpowered voice recognition. Nanotechnology, 2016. 27(49): p. 11.

165. Sultana, A., et al., Fabrication of wearable semiconducting piezoelectric nanogenerator made with electrospun-derived zinc sulfide nanorods and poly(vinyl alcohol) nanofibers. Translational Materials Research, 2016. 3(4): p. 11.

166. Zhu, J.X., L.Y. Jia, and R. Huang, Electrospinning poly(L-lactic acid) piezoelectric ordered porous nanofibers for strain sensing and energy harvesting. Journal of Materials ScienceMaterials in Electronics, 2017. 28(16): p. 12080-12085.

167. Wang, F.F., et al., High quality barium titanate nanofibers for flexible piezoelectric device applications. Sensors and Actuators a-Physical, 2015. 233: p. 195-201. 
168. Yang, Q., et al., Lead-free (Na0.83K0.17)(0.5)Bi0.5TiO3 nanofibers for wearable piezoelectric nanogenerators. Journal of Alloys and Compounds, 2016. 688: p. 10661071.

169. Chen, X., et al., 1.6 V Nanogenerator for Mechanical Energy Harvesting Using PZT Nanofibers. Nano Letters, 2010. 10(6): p. 2133-2137.

170. Cui, N.Y., et al., Magnetic Force Driven Nanogenerators as a Noncontact Energy Harvester and Sensor. Nano Letters, 2012. 12(7): p. 3701-3705.

171. Wu, W.W., et al., Lead Zirconate Titanate Nanowire Textile Nanogenerator for Wearable Energy-Harvesting and Self-Powered Devices. Acs Nano, 2012. 6(7): p. 6231-6235.

172. Gu, L., et al., Flexible Fiber Nanogenerator with $209 \mathrm{~V}$ Output Voltage Directly Powers a Light-Emitting Diode. Nano Letters, 2013. 13(1): p. 91-94.

173. Kang, H.B., et al., High Quality Mn-Doped (Na,K)NbO3 Nanofibers for Flexible Piezoelectric Nanogenerators. Acs Applied Materials \& Interfaces, 2014. 6(13): p. 1057610582. 